Review

\title{
Microscopic characterization of peptide nanostructures
}

\author{
Rashad Mammadov, Ayse B. Tekinay, Aykutlu Dana, Mustafa O. Guler* \\ UNAM-Institute of Materials Science and Nanotechnology, Bilkent University, Ankara 06800, Turkey
}

\section{A R T I C L E I N F O}

\section{Article history:}

Received 21 April 2011

Received in revised form 7 July 2011

Accepted 8 July 2011

\section{Keywords:}

Peptide

Nanofiber

Imaging

Nanomaterials characterization

\begin{abstract}
A B S T R A C T
Peptide-based nanomaterials have been utilized for various applications from regenerative medicine to electronics since they provide several advantages including easy synthesis methods, numerous routes for functionalization and biomimicry of secondary structures of proteins which leads to design of self-assembling peptide molecules to form nanostructures. Microscopic characterization at nanoscale is critical to understand processes directing peptide molecules to self-assemble and identify structure-function relationship of the nanostructures. Here, fundamental studies in microscopic characterization of peptide nanostructures are discussed to provide insights in widely used microscopy tools. In this review, we will encompass characterization studies of peptide nanostructures with modern microscopes, such as TEM, SEM, AFM, and advanced optical microscopy techniques. We will also mention specimen preparation methods and describe interpretation of the images.
\end{abstract}

(c) 2011 Elsevier Ltd. All rights reserved.

\section{Contents}

1. Introduction

2. Transmission electron microscopy (TEM).

3. Scanning electron microscopy (SEM)

4. Atomic force microscopy (AFM)....

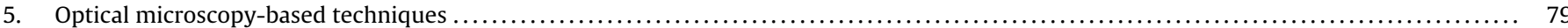

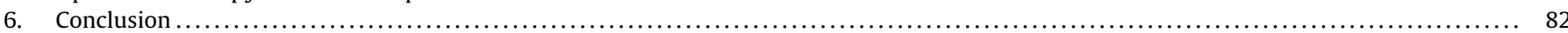

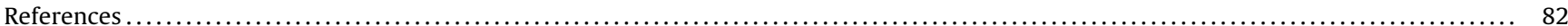

\section{Introduction}

Molecular mechanisms governing protein folding and formation of supramolecular assemblies by proteins inspired scientists to develop peptide-based nanomaterials with a wide variety of applications from electronics and nanocatalysis to tissue engineering and biosensors (Gazit, 2007; Guler and Stupp, 2007; Ulijn and Smith, 2008). The versatility of application areas is due to the flexibility of peptide design, which uses amino acids with different chemical functionalities. Moreover, self-assembly of peptide molecules led to formation of nanostructures which can be organized to form different higher-order structures such as hydrogels (Cui et al., 2010; Gazit, 2007), surface coatings (Adler-Abramovich et al., 2010), drug delivery systems (Sarikaya et al., 2003) and one-dimensional templates for synthesis of nanowires (Acar et al., 2011; Reches and Gazit, 2003) and nanotubes (Gazit, 2007). Pro-

\footnotetext{
* Corresponding author. Tel.: +90 312290 3552; fax: +90 3122664365

E-mail address: moguler@unam.bilkent.edu.tr (M.O. Guler).
}

cesses that govern the structural organization are programmed by non-covalent interactions between the amino acid residues. The side chains of the amino acids, which contain various chemical groups, determine the type of intramolecular and intermolecular interactions and drive formation of peptidic nanostructures. These interactions include hydrogen bonding, electrostatic, hydrophobic, $\pi-\pi$ and van der Waals interactions. Each of these interactions contributes in design and synthesis of self-assembled nanomaterials (Toksoz et al., 2010; Toksöz and Guler, 2009). Amino acid sequence determines types of interactions between peptides, which eventually leads formation of different secondary structures. For example, some amino acids favor formation of $\alpha$-helix, while some favor $\beta$-sheet or random coil structures. Properties of the final nanostructures are affected by the type of dominating secondary structure of the peptides. Peptidic nanostructures were previously discussed in four different groups as $\alpha$-helical based, $\beta$-sheet based, amphiphilic peptide based and collagen-like peptide nanostructures (Toksöz and Guler, 2009).

In regenerative medicine, peptide assemblies can be used as extracellular matrix (ECM) - mimicking materials for repairing 
damaged tissues. Peptide-based hydrogels have great advantage over other synthetic matrices since they allow versatility for conjugation of various bioactive properties (Dvir et al., 2011). Peptide amphiphile (PA) molecules have been used extensively for regenerative medicine studies (Webber et al., 2010). In physiological media, due to packing of hydrophobic alkyl tails, they can self-assemble into cylindrical nanostructures which make bundles and entanglements to form higher order structures resulting in hydrogels (Cui et al., 2010). These gels are comprised of meshwork of nanofibers which are capable of encapsulating up to $99 \%$ water, resembling native extracellular matrices. The PA nanofibers can be engineered to carry signals similar to the native environment of cells, providing an excellent platform for induction of cellular signaling mechanisms effectively (Stupp, 2010). Epitopes derived from natural ECM proteins or that allow binding to specific biological factors were conjugated to PA nanofibers and resulting synthetic matrices were used to induce angiogenesis (Rajangam et al., 2006), neural (Silva et al., 2004; Tysseling-Mattiace et al., 2008), bone (Mata et al., 2010), enamel (Huang et al., 2008) and cartilage regeneration (Shah et al., 2010) and survival of pancreatic islets (Chow et al., 2010). In these studies, activation of tissue-specific response with these hydrogels has been shown both in vitro and in vivo. Anti-cancer epitope carrying PAs have been shown to be internalized effectively by cancer cells while inhibiting their proliferation (Aulisa et al., 2009) or destroying them specifically (Standley et al., 2010). Nanostructures based on peptide molecules with hydrophobic and charged amino acids also form matrices and membranes in the physiological media (Zhang et al., 1993, 1995). These matrices were also shown to be promising for regenerative medicine studies such as wound healing (Schneider et al., 2008) and differentiation of neural stem cells (Gelain et al., 2006).

Peptide based nanostructures are also promising candidates for production of nanowires for electronics applications. Production of nanoelectronic devices requires synthesis of nanoscale wires. Amyloid-like, $\beta$-sheet-rich peptide nanofibers were extensively used for this purpose. Amyloid-like nanofibers were covalently attached through cysteine residues to gold particles, where resulting nanowires showed conductive properties, similar to electrical wires (Scheibel et al., 2003). Histidine-rich peptide nanotubes were used as templates for synthesis of conductivity-tunable $\mathrm{Cu}$ nanotubes through biomineralization (Banerjee et al., 2003). Biomineralization of titania and silica on amyloid-like peptide nanofibers were also reported recently (Acar et al., 2011). Bolaamphiphilic peptides, developed by Matsui and co-workers, are also suitable for nanoelectronics applications. They form nanotube structures, which capture metals and produce inorganic coating around nanotube (Matsui et al., 2000). Metalloporphyrin coating on these nanotubes has been achieved, which can be used in nanoscale sensors or photonics, due to porphyrin's high efficiency in electron and energy transfer (Matsui and MacCuspie, 2001).

Microscopic characterization gives valuable information about morphology and size of nanostructures. Both of these features are important in regenerative medicine, drug delivery, biosensor development and other applications, since functionality of designed nanostructures are significantly affected by these parameters. For example, in regenerative medicine studies, researchers try to manipulate cells by designing materials mimicking the native extracellular matrix. The ECM has characteristic anisotropic nanofibrillar structure, which has important roles in cellular behavior, including migration, signaling, proliferation and differentiation (Lutolf and Hubbell, 2005). For better cellular activity, researchers design ECM mimicking synthetic biomaterials with similar nanofibrous shape and size. In drug delivery applications, size and shape of nano-vehicles are important in determining their half-life in physiological environment and uptake into cells, which are directly related to efficacy of the delivery system (Farokhzad and Langer,
2009). Precise information about size and shape of nanostructures synthesized for the above mentioned purposes is crucial, since nanoscale aberrations in these properties interfere with functionality.

Advancement in microscopy techniques has paved the way for development of nanotechnology, materials science, molecular biology and other growing fields. For example, improvements in atomic force microscopy (AFM) now allows visualization of nanostructures in solution, which enables analyzing them in their native environment and avoiding artifact images caused by drying effect during specimen preparation and strong capillary action between sample and AFM probe (Fotiadis et al., 2002). Moreover, imaging nanoparticles in cells, understanding mechanical features of biological molecules such as nucleic acids, proteins and polymers, and generating stiffness maps of biological surfaces were all made possible with the use of modern AFMs (Dong et al., 2009; Husale et al., 2009; Sahin et al., 2007; Tetard et al., 2008). Dip-pen nanolithography technique, which brought significant advancement in functionalization of surfaces at nanoscale, is another achievement made through improvement of AFM proving potential use of microscopes for purposes other than imaging (Piner et al., 1999).

Modern sensitive microscopes together with accurate specimen preparation techniques allow us to determine size and shape of nanostructures accurately. There are several imaging techniques that can be used for characterization of nanostructures and each technique has advantages and disadvantages (limitations), so it is important to understand these and choose the right one for the desired characterization. A comparison of these techniques is provided in Table 1. In this review, we examine microscopy techniques used for characterization of peptide nanostructures in four main parts: transmission electron microscopy (TEM), scanning electron microscopy (SEM), atomic force microscopy (AFM) and optical microscopy-based techniques. Sample preparation methods and information obtained from images are also emphasized.

\section{Transmission electron microscopy (TEM)}

Analysis of size and morphology of peptide nanostructures with high resolution at a scale of a few nanometers or even below can be performed by TEM. This technique involves transmission of an electron beam through the specimen, which interacts with internal structures thus collecting information for image generation. Since wavelength of electron beam is smaller than that of light, TEM allows imaging with higher magnification and resolution than light microscopy and enables observation of internal structures of materials. Detailed working mechanism of TEM can be found in reference Egerton (2005). TEM is used to identify the very details about nanometer scale structures and even to perform atomic resolution characterization of materials, which involves not only structural characterization but also identification of elemental composition and chemical bonding (Urban, 2008).

This technique is based on transmission of electrons through specimen, which should be thin to get good quality images. Imaging of bulky samples such as hydrogels with TEM needs special sample preparation techniques in order to prevent image artifacts. The easiest way is to directly apply gel samples on TEM grid (cupper grid). In previous studies, $1 \mathrm{wt} \%$ peptide amphiphile (PA) nanofiber gel was applied onto cupper grids and stained with phosphotungstic acid (PTA) (Guler et al., 2005). The nanofibers within the gel were $7 \mathrm{~nm}$ in diameter and several hundreds of nanometers in length. In another study, bolaamphiphilic peptide nanostructures were investigated similarly, with an exception that both negative (PTA) and positive (uranyl acetate) staining were performed (Claussen et al., 2003). Here, nanofibers with 5-8 nm in diameter were observed with both staining methods. Uranyl 
Table 1

Comparison of microscopy techniques.

\begin{tabular}{|c|c|c|c|c|}
\hline Properties & TEM & SEM & AFM & Optical microscopy \\
\hline Advantages & $\begin{array}{l}\text { Provides very high (even } \\
\text { atomic) resolution and } \\
\text { magnification } \\
\text { Enables visualization of } \\
\text { detailed structures such as } \\
\text { subcellular structures }\end{array}$ & $\begin{array}{l}\text { Allows imaging bulky samples } \\
\text { and three dimensional surfaces }\end{array}$ & $\begin{array}{l}\text { Allows three dimensional } \\
\text { imaging } \\
\text { Easy sample preparation } \\
\text { Allows imaging at wet } \\
\text { conditions, enables live } \\
\text { specimen observation }\end{array}$ & $\begin{array}{l}\text { Fluorescent and polarized } \\
\text { imaging options } \\
\text { Color can be observed } \\
\text { Less expensive } \\
\text { Allows imaging of live } \\
\text { specimens }\end{array}$ \\
\hline Disadvantages & $\begin{array}{l}\text { Requires laborious sample } \\
\text { preparation, resin embedding } \\
\text { and sectioning for bulky } \\
\text { samples } \\
\text { Due to thin and two } \\
\text { dimensional specimen } \\
\text { requirements, not suitable for } \\
\text { imaging three dimensional } \\
\text { arrangements of } \\
\text { nanostructures in bulky } \\
\text { samples } \\
\text { Does not allow live specimen } \\
\text { imaging due to vacuum }\end{array}$ & $\begin{array}{l}\text { Limited resolution at nanoscale } \\
\text { Gives information only about } \\
\text { surface of the specimen } \\
\text { Does not allow live specimen } \\
\text { imaging due to vacuum }\end{array}$ & $\begin{array}{l}\text { Image generation is slow } \\
\text { Size of observed structures } \\
\text { depends on tip radius, if tip } \\
\text { radius is not low enough wrong } \\
\text { size measurements can be } \\
\text { made for nanoscale structures }\end{array}$ & Low resolution \\
\hline Resolution limit & $\begin{array}{l}0.2-0.5 \mathrm{~nm} \text { with conventional } \\
\text { TEM, } 1 \text { A with HR-TEM }\end{array}$ & $\sim 10 \mathrm{~nm}$ & $\begin{array}{l}\text { Depends on tip radius, could be } \\
\text { smaller than } 1 \mathrm{~nm}\end{array}$ & $\sim 200 \mathrm{~nm}$ \\
\hline Sample type & $\begin{array}{l}\text { Nanofibers, nanoparticles, } \\
\text { fixed cells and subcellular } \\
\text { structures }\end{array}$ & $\begin{array}{l}\text { Three dimensional structure of } \\
\text { hydrogels, nanofiber networks, } \\
\text { cells encapsulated in } \\
\text { biomaterials }\end{array}$ & $\begin{array}{l}\text { Nanoparticles, nanofibers, } \\
\text { living or fixed cells and } \\
\text { subcellular structures }\end{array}$ & $\begin{array}{l}\text { Fluorescently labeled proteins, } \\
\text { amyloid fibrils etc. }\end{array}$ \\
\hline Sample preparation & $\begin{array}{l}\text { Staining is required for organic } \\
\text { structures (e.g. PTA or uranyl } \\
\text { acetate) }\end{array}$ & $\begin{array}{l}\text { Less destructive methods for } \\
\text { three dimensional structures } \\
\text { such as critical point drying, } \\
\text { freeze drying followed by } \\
\text { coating with a few nanometers } \\
\text { of } \mathrm{Au} / \mathrm{Pd}\end{array}$ & $\begin{array}{l}\text { Air drying or a few min } \\
\text { incubation is sufficient for } \\
\text { imaging in the air } \\
\text { Immobilization is required for } \\
\text { wet imaging }\end{array}$ & $\begin{array}{l}\text { Fluorescent labeling with } \\
\text { antibodies or chemicals }\end{array}$ \\
\hline Sample fixation & $2 \%$ glutaraldehyde and $\mathrm{OsO}_{4}$ & $\begin{array}{l}2 \% \text { glutaraldehyde solution ( } 3 \% \\
\text { sucrose in PBS) }\end{array}$ & $2 \%$ glutaraldehyde & 4\% PFA, acetone, methanol \\
\hline
\end{tabular}

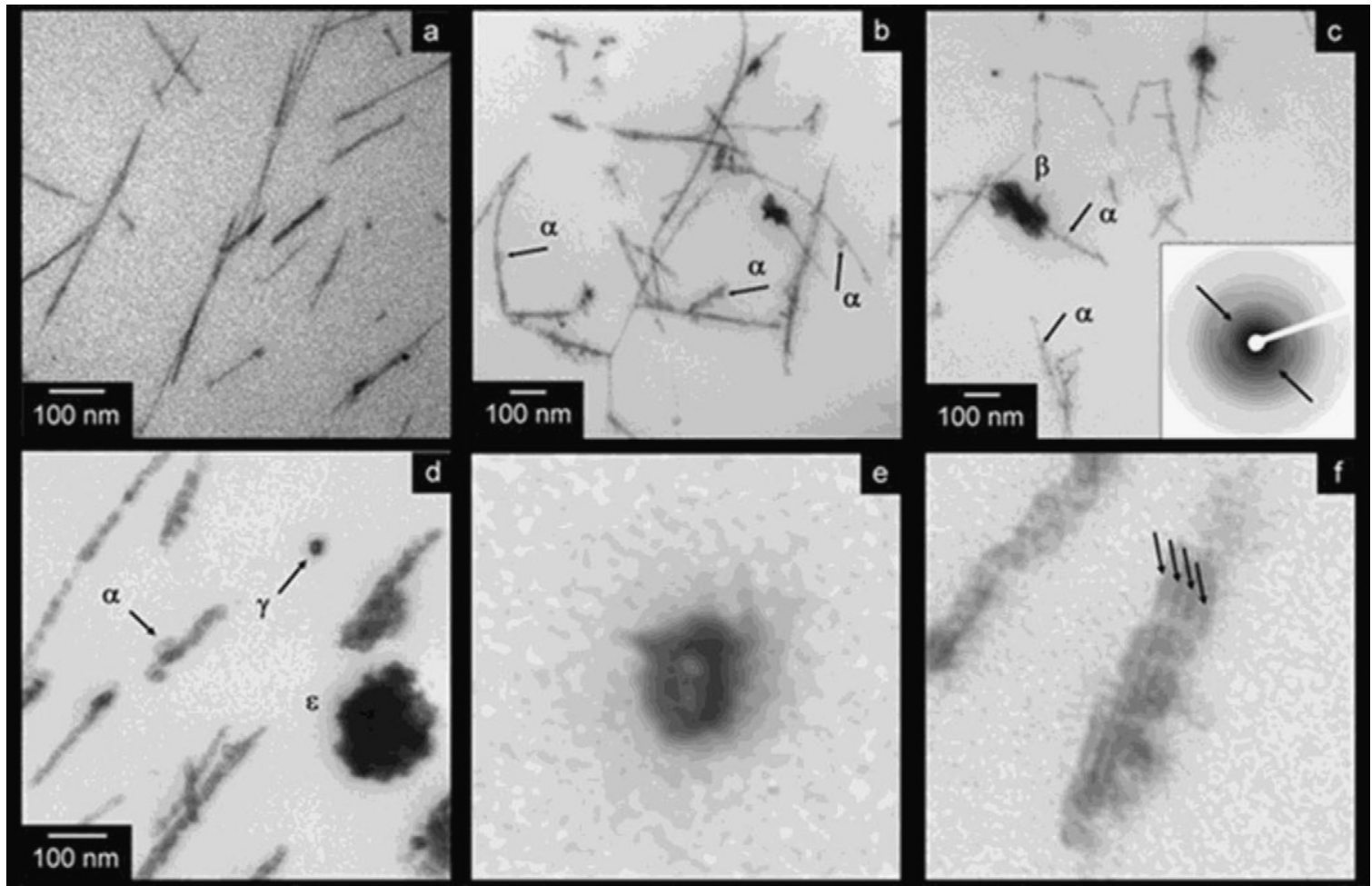

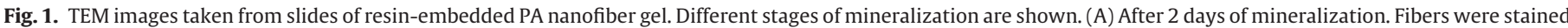

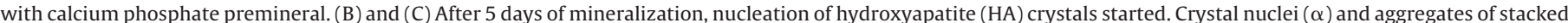

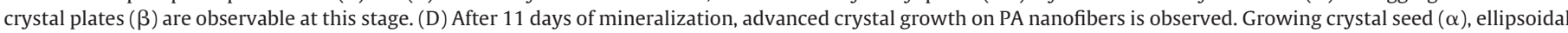

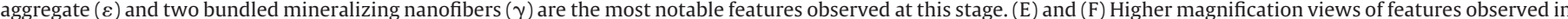

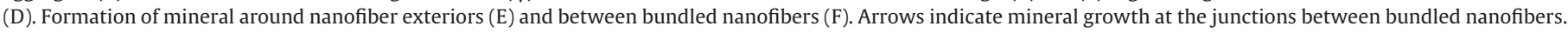
Reprinted with permission from Spoerke et al. (2009). Copyright @ 2009 John Wiley \& Sons, Inc. 

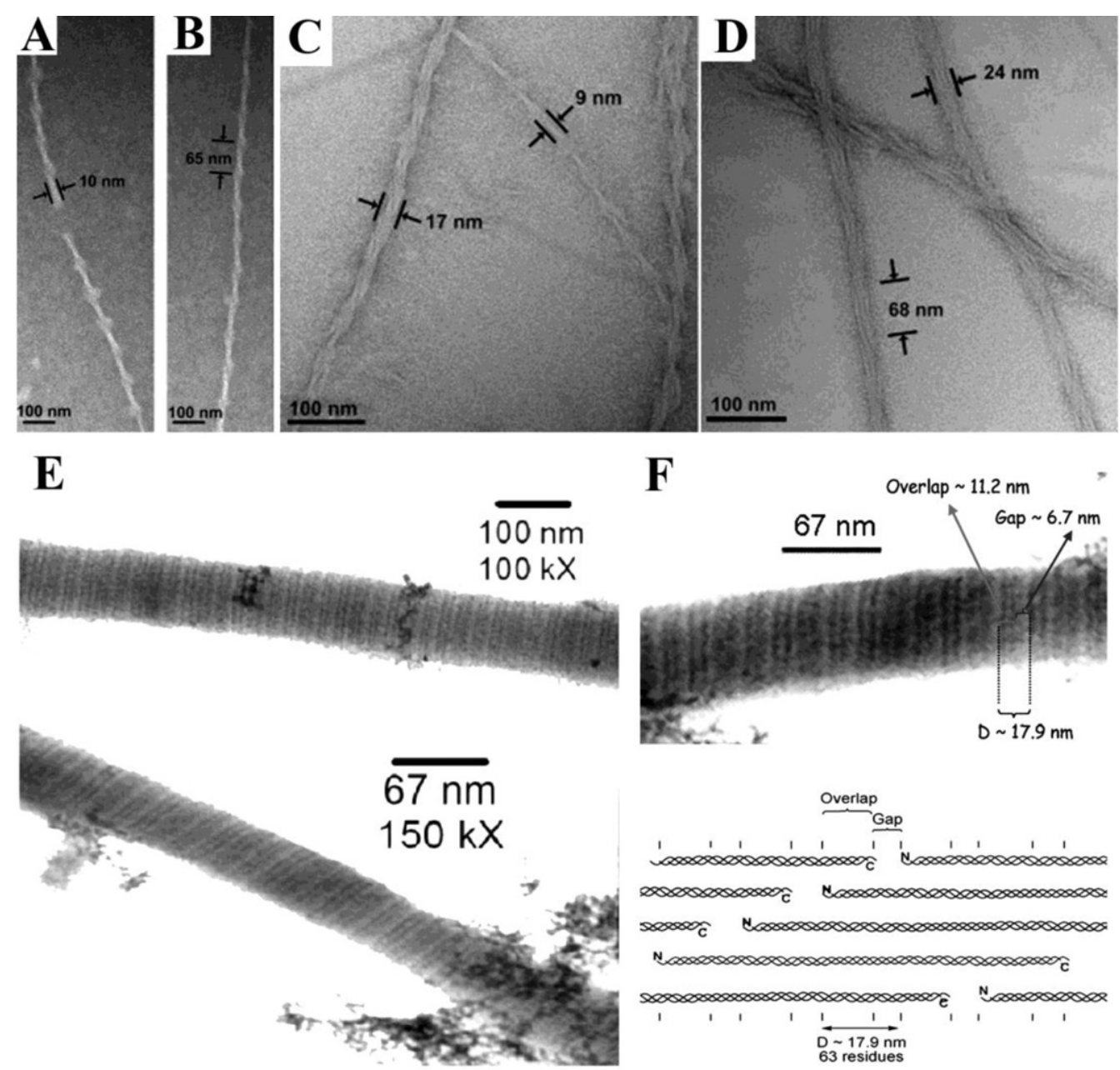

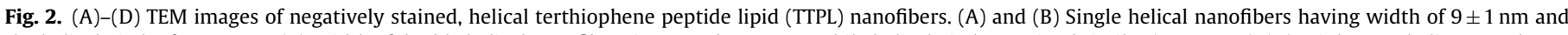

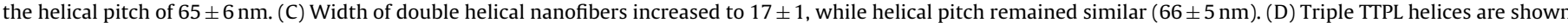

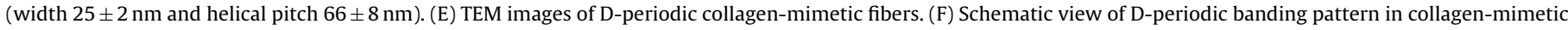
fibers and relationship between peptide oligomers forming these fibers. Each D-period includes a "gap" zone and a larger "overlap" zone.

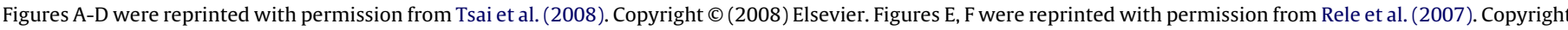
(C) (2007), American Chemical Society.

acetate, binding preferentially to acid groups on nanofibers, stained both core and periphery of bolaamphiphilic nanofibers with carboxylic acid groups extending from both sides of bolaamphiphiles (Claussen et al., 2003). However, only periphery of the nanostructures was stained when carboxylic acid groups were located on only one side of bolaamphiphiles. Another method for sample preparation is embedding gels into resin. PA nanofiber gels, which were embedded into EPON ${ }^{\mathrm{TM}}$ (epoxy) resin and sectioned with microtome, were visualized by TEM (Hartgerink et al., 2001). By this method, it was possible to follow different stages of mineralization, while observing aggregates of stacked crystal plates, crystal nuclei and advanced crystal growth on PA nanofibers (Fig. 1) (Spoerke et al., 2009). An alternative method is diluting gel and applying diluted solution onto copper grid. This method aims to avoid imaging of aggregated nanostructures, while observing individual features on the surface. For this purpose, $1 \mathrm{wt} \%$ PA gels were diluted and dropped onto carbon grids (Guler et al., 2006). After a few minutes excess solution was removed with filter paper, negative staining with PTA was performed, samples were air dried and imaged with $200 \mathrm{kV}$. In another study by Tsai et al., self-supporting gels were formed and diluted 15-fold. After drying of the sample on TEM grid, staining was performed by using uranyl acetate. This method allowed imaging helical peptidic nanostructures, which have applications in nanoelectromechanical systems (NEMS), and measuring important structural parameters, such as helical size and pitch (Fig. 2A-D) (Tsai et al., 2008). Single, double and triple helical structures were clearly observable (Tsai et al., 2008). Rajangam et al. (2008) reported another interesting method for observing the nanofibrous nature of peptide gel where carbon grid was dipped into $1 \mathrm{wt} \%$ PA gel suspension twice for $20 \mathrm{~s}$ and then stained with PTA.

There are also numerous studies where TEM was used for imaging peptide nanostructures in solution form, which is less challenging regarding preparation of thin samples. In one study, $0.01 \mathrm{wt} \%$ of peptidic thiophene molecules, which form onedimensional nanostructures with potential applications in organic electronic devices, were dropped onto copper TEM grids and dried. Samples were stained with uranyl acetate for $15 \mathrm{~min}$ and one-dimensional nanostructures with $6-7 \mathrm{~nm}$ width were clearly observed at $100 \mathrm{kV}$ (Stone et al., 2009). Dolphin et al. (2006) stained amyloid protofibrils with a similar method while using $2 \%$ uranyl acetate. By using similar method, peptidic fibrillar and micellar nanostructures with 5-20 nm size were observed (Guler and Stupp, 2007). Rele et al. (2007) designed collagen-mimetic peptides with D-periodicity and reported that $0.5 \%$ uranyl acetate staining for $10 \mathrm{~s}$ was sufficient to provide contrast for TEM imaging (Fig. 2E). Image resolution was sufficient to measure size of D-periods on collagen-mimetic fibers (Fig. 2F). Peptide amphiphile molecule 
carrying light-sensitive moiety self-assembled into different morphology upon light triggering and both of the nanosphere and nanofiber forms were observed by air drying of the PA solution $(0.4 \mathrm{mM})$ on the substrate and staining with uranyl acetate (Muraoka et al., 2009). Another method for visualization of PA nanofibers involves induction of nanofiber formation on a TEM grid. Hartgerink et al. placed $10 \mu \mathrm{L}$ of $0.01-0.02 \%$ solution of PA directly on the grid. The grid was then placed into a sealed chamber with $\mathrm{HCl}$ vapors for 10 min for nanofiber formation after which the grids were washed with deionized water. Sample was stained with phosphotungstic acid or uranyl acetate (Hartgerink et al., 2002). In another study, $1 \mu \mathrm{L}$ of $0.1 \mathrm{wt} \% \mathrm{PA}$ solution in aqueous media was drop casted onto a carbon-coated copper grid. The samples on the grid were stained for 1-3 min in phosphotungstic acid, gently rinsed in water and blotted dry (Hsu et al., 2008). This enabled observation of nanofibers within 5-8 nm range. Vesicular structures (50-450 $\mathrm{nm}$ ) formed by self-assembly of dipeptides were visualized by negative staining with uranyl acetate (Mishra et al., 2008). Authors concluded that there is a high density of negative charges on vesicles since there was grayscale contrast between vesicle surface and grid background. Positively charged vesicles showed lighter staining than background. Use of negative staining helped to clarify these fine features. Lim et al. (2008) observed nanoribbons composed of $\beta$-sheet forming and bioactive peptide sequences designed for encapsulation of hydrophobic drugs by TEM imaging. After 1 min treatment of TEM grid with peptide solution, remaining solution was removed with filter paper and positive staining was performed with ruthenium tetroxide.

Sometimes pre-fixation step is necessary during sample preparation to conserve delicate structures such as subcellular organelles and to protect complex three-dimensional nanostructures from effects of sample preparation (e.g. drying). Beniash et al. (2005) visualized entrapment of mammalian cells in peptide amphiphile nanofiber matrix by using TEM. Fixation with glutaraldehyde and $\mathrm{OsO}_{4}$ and dehydration steps preceded sample preparation, which included embedding in epoxy resin and ultrathin sectioning. A similar method was also used to visualize peptide-hyaluronic acid sac structures (Capito et al., 2008).

Metal-binding peptide nanofibrils provide a good template for tailored growth of metal particles on them, which is a smart method for nanowire synthesis. Peptide nanofibrils with metalbinding sites have affinity to different metals such as silver, gold and platinum depending on amino acid sequence (Kasotakis et al., 2009). Metal-bound nanofibers were observed by using TEM without any need for staining to increase contrast, since metals provide contrast (Fig. 3). Peptide amphiphile nanofibers are among the peptide-based nanostructures which are good templates for mineralization. Bright-field TEM imaging of various $\mathrm{Cd}^{2+}-\mathrm{PA}$ mixtures revealed that $\mathrm{Cd}^{2+}$ ions grow homogenously on PA nanofibers (Sone and Stupp, 2004). $\mathrm{Cd}^{2+}$ ions provided necessary contrast without further staining. Peptide amphiphiles, which were designed as MRI contrast agents, form nanofibers and nanomicelles with higher relaxivity time than known monomeric MR contrast agents (Bull et al., 2005). This contribution is probably caused by higher order structures formed by monomeric peptide amphiphiles which chelate Gd(III) ions effectively. Visualization of nanofiber structures with Gd(III) ions did not need any staining either, since Gd (III) ions themselves provide contrast. Carny et al. reported that linker amino acids such as cysteine (bearing thiol groups) allowed ordered organization of gold nanoparticles on diphenylalanine peptide nanotubes. These gold coated nanotubes were also imaged by TEM with high contrast without any further staining (Carny et al., 2006). Coating nanostructures with appropriate metals is a convenient way of increasing contrast. Contrast of nanofibrous structures, with a diameter of $12 \mathrm{~nm}$, was increased by using platinum coating after drying of the sample (either gel or diluted suspension) on TEM grid (Smeenk et al., 2005). Ryadnov et al. (2003) observed peptidemediated assembly of gold nanoparticles by using TEM, where nanoparticles were observed to be separated with homogenous distances $(7 \mathrm{~nm})$ from each other. In this study, nanoparticle-peptide solution on carbon was dried with filter paper without further staining for sample preparation. Although gold nanoparticles were clearly observed, peptide nanostructures holding them together were not observable.

In order to get rid of the negative effects of drying, QFDE-TEM protocol can be used for sample preparation. In this technique, samples are frozen at $-195^{\circ} \mathrm{C}$, after which they are fractured in freeze-fracture apparatus. After etching at $-95^{\circ} \mathrm{C}$, samples are coated with platinium/carbon mixture. Elongated nanostructures formed by mixing peptide amphiphile and oligo(phenylene ethynylene) were observed by this method (Bull et al., 2008).

High-resolution field emission gun TEM (HR-TEM) is an imaging method which enables visualization of crystallographic structure of materials at nanoscale. Resolution that can be reached with this method is below $1 \AA$ A. Sone et al. used HR-TEM to visualize lattice structure of CdS nanocrystals grown on PA nanofibers (Fig. 4A). HRTEM was also used to visualize negatively stained (uranyl acetate) peptide nanotubes (Reches and Gazit, 2003). In this example, HRTEM provided indication of the regular structures of the tube walls. Moreover, silver-filled peptide nanotubes for nanowire production were visualized without staining, since again silver provided required contrast.

Cryo-TEM is another powerful technique to observe peptide nanostructures in their native state (Hartgerink et al., 2001). In one study, hydrogels formed by self-assembly of $\beta$-hairpin peptides were snap-frozen by liquid ethane and imaged by cryo-TEM (Schneider et al., 2002). Cryogenic system holds temperature constant at $-170^{\circ} \mathrm{C}$, preventing sublimation of the sample. Structures were imaged while underfocused in order to enhance contrast and nanofibrous nature of the scaffold was observed by this method. In another study, morphological transformation of nanostructures from twisted ribbons into helical ribbons was observed (Pashuck and Stupp, 2010). Pashuck et al. (2010) rapidly froze thin layers of peptide amphiphile solutions in liquid ethane to preserve morphological structures and to avoid drying effect. By using this method, nanofibers with 8-10 nm diameters were observed (Fig. 4C). CryoTEM provides valuable information which cannot be obtained with techniques based on sample drying. Cui et al. (2009) observed the flexible structure of nanobelts which arise as tilts, flippings and entanglements in morphology (Fig. 4B). In this method, contrast related to different tilt angles of nanobelts was observed (Fig. 4D). At $90^{\circ}$ tilt angle (nanobelt surface is parallel to electron beam), electrons travel the longest distance in nanobelts and the highest contrast is achieved.

EF-TEM is an improved electron microscopy system, which can filter scattered electrons in a specimen according to energy, besides scatter angle. Different energy windows can be used for filtering process and selecting electrons (Kohl and Reimer, 2008). Energy-based selection of contrast might allow achieving elemental contrast. This method allows imaging without further staining with sufficient contrast. Kogiso et al. (2000) used EF-TEM for examination of fine structures in hydrogels and produced high-contrast images without staining.

In summary, TEM imaging allows successful imaging of peptide nanostructures, which are a few nanometers in size, by using different specimen preparation techniques for increasing image contrast. Modern versions of TEM can even visualize nanostructures in solution (cryo-TEM) or crystallographic structures at angstrom level (HR-TEM). TEM can be used for detailed morphological and structural analysis of nanostructures at a scale of a few nanometers or below. 

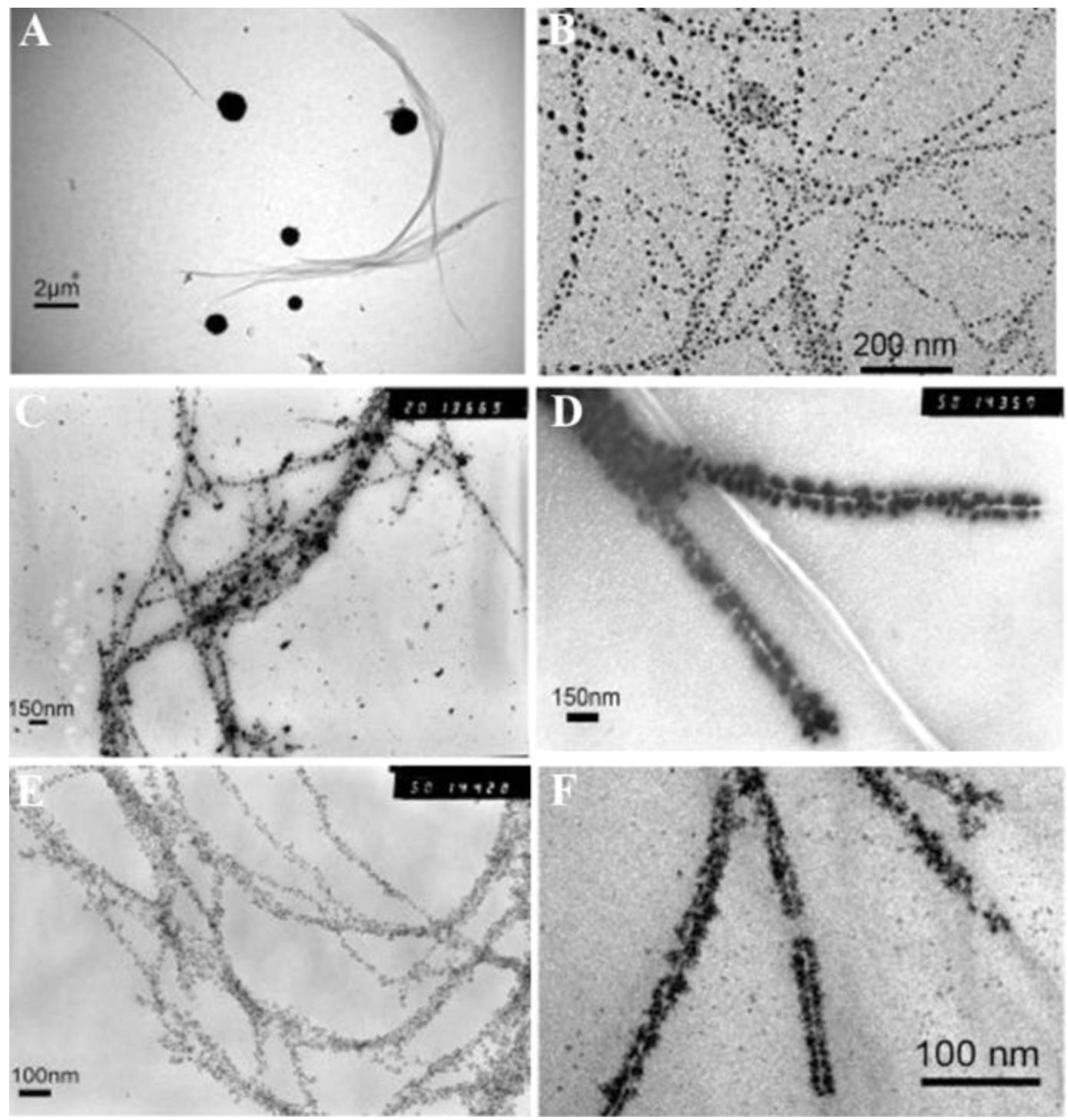

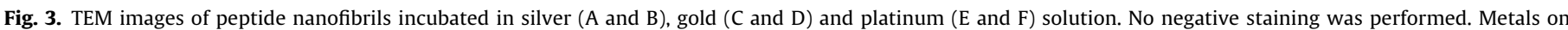
nanofibrils provided sufficient contrast.

Reprinted with permission from Kasotakis et al. (2009). Copyright @ (2009), John Wiley \& Sons, Inc.

\section{Scanning electron microscopy (SEM)}

When specimen is too thick for TEM imaging, using SEM is a more appropriate choice to get high resolution images. Unlike TEM, SEM uses electrons reflected from surface of sample as signals for image generation. Detailed information about working principle of SEM is explained in reference Pease (2008). SEM can provide information about surface topography, crystalline structure, chemical composition and electrical behavior of an almost $1 \mu \mathrm{m}$ slice on the surface of the sample (Vernon-Parry, 2000). Moreover, sample preparation techniques for SEM are less destructive than TEM. Therefore, it is better to use SEM for observing bulky samples (Vernon-Parry, 2000). ECM-mimicking biomaterials formed by non-covalent interactions of peptide nanofibers can be considered as examples for this type of bulky samples. In order to increase contrast and resolution of imaging of these hydrogels, specimen preparation is a critical step. For effective specimen preparation, the first requirement is dehydration of the sample without destructing the three-dimensional structure of the hydrogel. Air drying of hydrogels causes collapsing of the nanofiber network, which hinders our understanding of three-dimensional structure and porosity of the material (Mahler et al., 2006) (Fig. 5A). Network dehydration by ethanol treatment and critical point drying help in solving this problem (Spoerke et al., 2009). This method enabled observation of three-dimensional nanofiber network comprising peptide amphiphile gels (Fig. 5B) (Rajangam et al., 2006; Spoerke et al., 2009). In these studies, coating specimens with a very thin layer of ( $3 \mathrm{~nm}$ ) gold-palladium alloy increased contrast of nanostructures and quality of images. Another method for dehydration of hydrogels is freeze-drying. Although three-dimensional structures might be distorted this method, Xu and Kopecek (2008) achieved to get fine images of meshwork structure formed by self-assembled triblock polypeptides (Fig. 5C). This method includes snap-freezing of hydrogel samples with liquid nitrogen, freeze-drying of frozen hydrogel and coating of samples with gold.

Adler-Abramovich et al. (2006) visualized nanotube structures formed by self-assembly of diphenylalanine units by SEM $(5 \mathrm{kV})$. For sample preparation, peptide solution was dropped onto a glass coverslip, air-dried and coated with gold. Individual nanotubes reaching $80 \mathrm{~nm}$ in size were observed by this method. Ryadnov et al. visualized individual peptide nanofibers, which are $50 \mathrm{~nm}$ in thickness. Peptide nanofiber suspension was deposited onto 

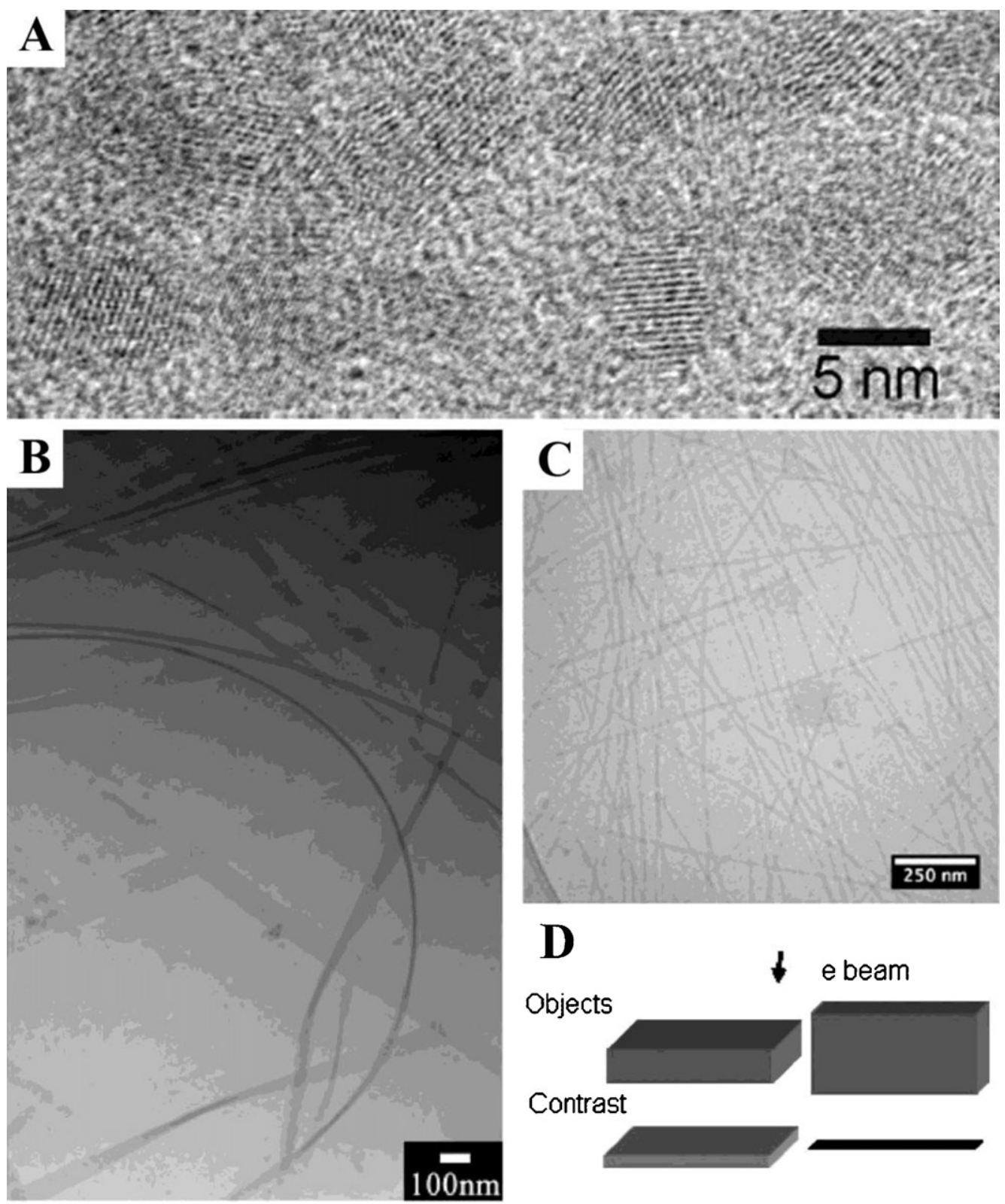

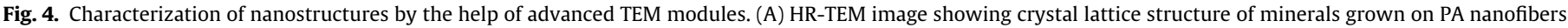

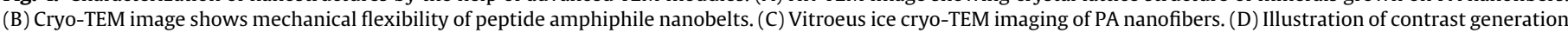

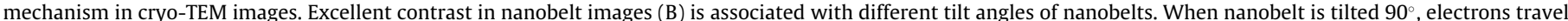
maximum distance in nanobelt and have the highest possibility to be scattered (darker lines in image).

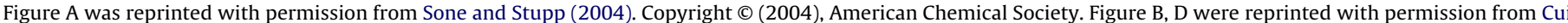

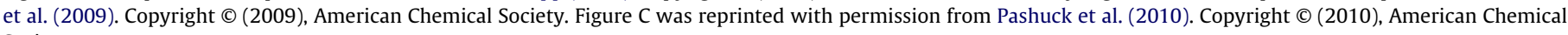
Society.
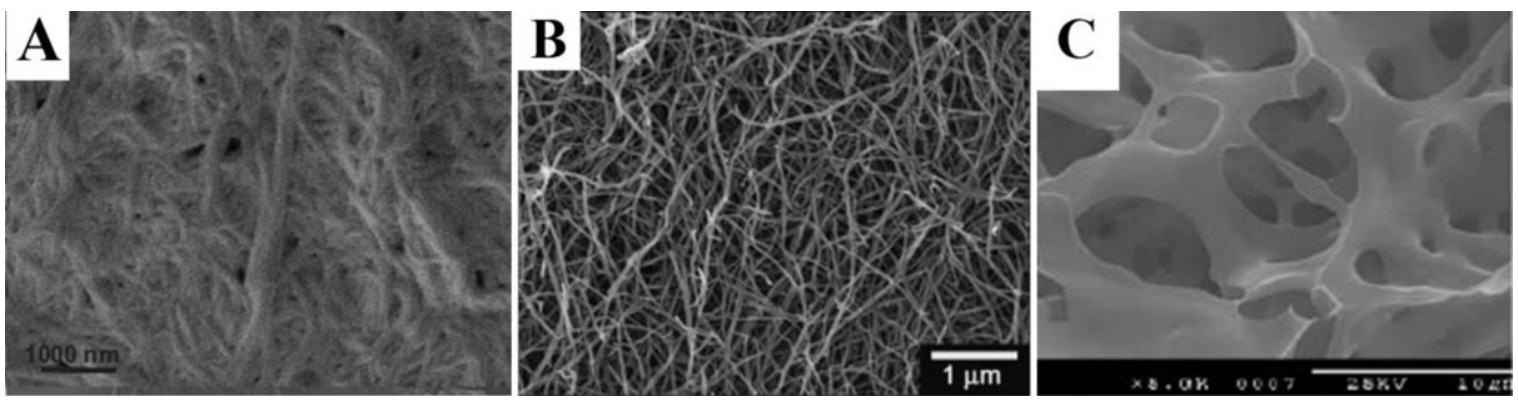

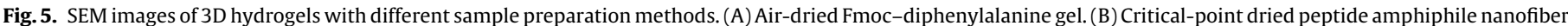
gel. (C). Freeze-dried triblock polypeptide hydrogel.

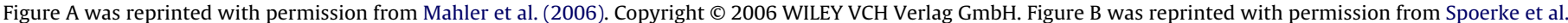
(2009). Copyright @ (2009), John Wiley \& Sons, Inc. Figure C was reprinted with permission from Xu and Kopecek (2008). Copyright @ (2008), Springer. 
carbon-coated grids by air drying and visualized by SEM after staining with uranyl acetate (Ryadnov and Woolfson, 2003). Branching of nanofibers, which self-assembled from branched peptides, could be identified through this method.

Peptide membranes, which are formed by adding peptide solution in hyaluronic acid (or hyaluronic acid/heparin) solution, provide another example for higher order structures formed by peptide nanofibers. Here, pre-fixation with $2 \%$ glutaraldehyde solution (3\% sucrose in PBS) before network dehydration and critical point drying steps are required in order to preserve membrane and sac structures (Capito et al., 2008; Chow et al., 2011). Cross-section of membranes can be observed by cutting sacs in half. PA nanofiber - Ti foam hybrid structures were also pre-fixed with glutaraldehyde and formaldehyde solutions (Sargeant et al., 2008a).

Peptide nanoparticles are another example of nanostructures which can be observed by SEM. Liu et al. used field emission SEM in order to image antimicrobial peptide nanoparticles with sizes of less than $150 \mathrm{~nm}$. For sample preparation, nanoparticle solution was dropped onto a silicon wafer and air-dried at room temperature. Dried samples were coated with platinum before imaging (Liu et al., 2009).

Modern SEM instruments include more sophisticated versions such as HR-SEM (high resolution SEM), E-SEM (environmental SEM) and cryo-SEM (cryogenic SEM) which are used for various purposes. Mahler et al. (2006) reported that Fmoc-diphenylalanine (FF) units form gels at higher concentrations (1 wt\%) which consist of fibrous networks. HR-SEM and E-SEM were used to analyze three-dimensional morphology of these hydrogels. Flexibility of individual fibers can be recognized from HR-SEM images. To image non-conducting samples, E-SEM seems to be a better choice, since it does not include any treatments (staining or coating) for sample preparation. Unlike conventional SEM, sample is located in a chamber with high pressure rather than vacuum. Images of FF gel obtained by E-SEM confirmed existence of a fibrillar network under humid conditions (Mahler et al., 2006).

In addition, peptide nanostructures can also be visualized by using cryo-SEM. Cryo-SEM involves snap-freezing of sample in order to observe nanostructures in solution form. Nanofiber gels formed by Fmoc-dipeptides were observed by cryo-SEM and diameters of nanofibers were measured (Fig. 6A). Since this value was well above the diameter of Fmoc dipeptide building block, authors concluded that observed nanofibers were bundles of supramolecular aggregates of dipeptides (Jayawarna et al., 2006).

Visualization of supramolecular structures encapsulated in membranous structures such as liposomes can be achieved by using a special technique for specimen preparation, called quickfreeze/deep-etch (QFDE). Light-induced PA nanofibers in liposomes were visualized with SEM imaging by using this sample preparation method (Lee et al., 2008). This technique produces replicas from the fractured surface of a rapidly frozen sample. After fracture, the etching process sublimates water from the surface, exposing structures otherwise hidden in ice. The PA nanofiber network was observed from fractured parts of surfaces (Fig. 6B).

Imaging cells in nanofiber gels is another issue that was solved by special sample preparation protocols and sophisticated SEM techniques. To image cells on PA nanofiber scaffolds, fixation is necessary. Shah et al. used ethanol dehydration and critical point drying after fixation. Mesenchymal stem cells adhered onto PA nanofiber network were visualized by using this method (Fig. 6C) (Shah et al., 2010). E-SEM is also a good instrument for imaging biological entities such as cells entrapped in nanofiber matrix. Chondrocytes cultured in gel were imaged in their native form (hydrated) by using E-SEM (Fig. 6D) (Jayawarna et al., 2006).

SEM is a microscopy technique widely used for observation of thicker samples such as three-dimensional structure of hydrogels, cells entrapped in nanofiber matrices or relatively bigger individual nanostructures. Thus, it should be exploited to analyze the bulky nature of higher-order structures formed by peptide nanostructures.

\section{Atomic force microscopy (AFM)}

AFM involves scanning of surface with a cantilever, typically made of silicon nitride for biological applications, whose deflections are recorded by computer to generate image (Engel et al., 1999). More information about the basic mechanism of AFM can be found in reference Alessandrini and Facci (2005). Pyramidal tip at the end of cantilever can be sufficiently sharp to achieve resolution of less than $1 \mathrm{~nm}$. AFM has several advantages over other microscopy techniques. First of all, sample preparation for AFM is easier, since it does not need any pretreatment of specimen such as staining, labeling or coating (Allison et al., 2010). Moreover, images obtained with AFM can be demonstrated in a three-dimensional format. Another advantage is that cells and biomolecules can be imaged in a physiologically relevant environment without freezing or any other treatment (Allison et al., 2010).

For AFM imaging of peptide nanostructures, silicon wafer or freshly cleaved mica can be used as substrate. Bull et al. prepared the sample by drop casting $0.05 \mathrm{wt} \%$ dilute aqueous solution of peptide molecules onto freshly cleaved mica (Stone et al., 2009). AFM images showed that these molecules form one-dimensional nanostructures with 5-10 nm width and height. Similarity of width and height has led authors to suggest that nanostructures have cylindrical shape. Guler et al. (2005) used $10 \mu \mathrm{L} 0.1 \mathrm{wt} \%$ solution of PA and drop casted the sample onto silicon wafer which was pre-cleaned by ultrasonication in water and isopropanol. Aggregated view of nanofiber bundles could be observed from this image. In another study, samples were prepared from $2 \mathrm{wt} \%$ peptide amphiphile solution, initially gelled, and then diluted to $0.1 \mathrm{wt} \%$ (Hsu et al., 2008). These samples were later drop casted onto pre-cleaned silicon wafer and air dried. AFM was performed in tapping mode and peptide nanofibers with $5 \mathrm{~nm}$ diameter were clearly observable. Zhou et al. visualized Fmoc-based peptide hydrogels by diluting and dropping onto mica surface. Water was removed by capillary action, and samples were washed and imaged with tapping mode AFM (Zhou et al., 2009). Interwoven network of nanofibers and bundles observed in this study suggested that Fmoc-based peptide hydrogels possess a three-dimensional nanofibrous structure. Sargeant et al. coated NiTi (nickel-titanium) surfaces with bioactive PA nanofibers for biofunctionalization of implant surfaces. AFM imaging was performed by using tapping mode and showed that PA nanofibers coated the NiTi surfaces homogenously (Sargeant et al., 2008b). Bull et al. (2008) used mica surface in another study where $0.1 \mathrm{wt} \%$ solution was drop casted and rest of the solution was removed and air dried. Peptide nanofibers and nanoparticles with nearly $5 \mathrm{~nm}$ height were observed by this method. In another study, $\beta$-amyloid peptides were deposited onto freshly cleaved mica surface and washed with water after $1.5 \mathrm{~min}$ (Cohen et al., 2006). Formation of several microns long and a few nanometers wide amyloid fibrils after polymerization phase was observed by this way. Moreover, inhibition of polymerization by indole derivatives was also deduced from AFM images taken (Cohen et al., 2006). To image reassembly of bolaamphiphilic peptides forming nanofibers after their breakdown with sonication, tapping mode AFM was used (Qiu et al., 2008). Samples were washed away from mica surface after a few seconds of incubation and air dried. AFM imaging showed that length of peptide nanofibers were increased from $\sim 300 \mathrm{~nm}$ to $\sim 800 \mathrm{~nm}$ after 25 days, which indicates reassembly of broken nanofibers.

AFM images can also provide information about secondary structures formed by peptides. It is possible to determine right or left handedness of helical structures formed by peptide nanostruc- 

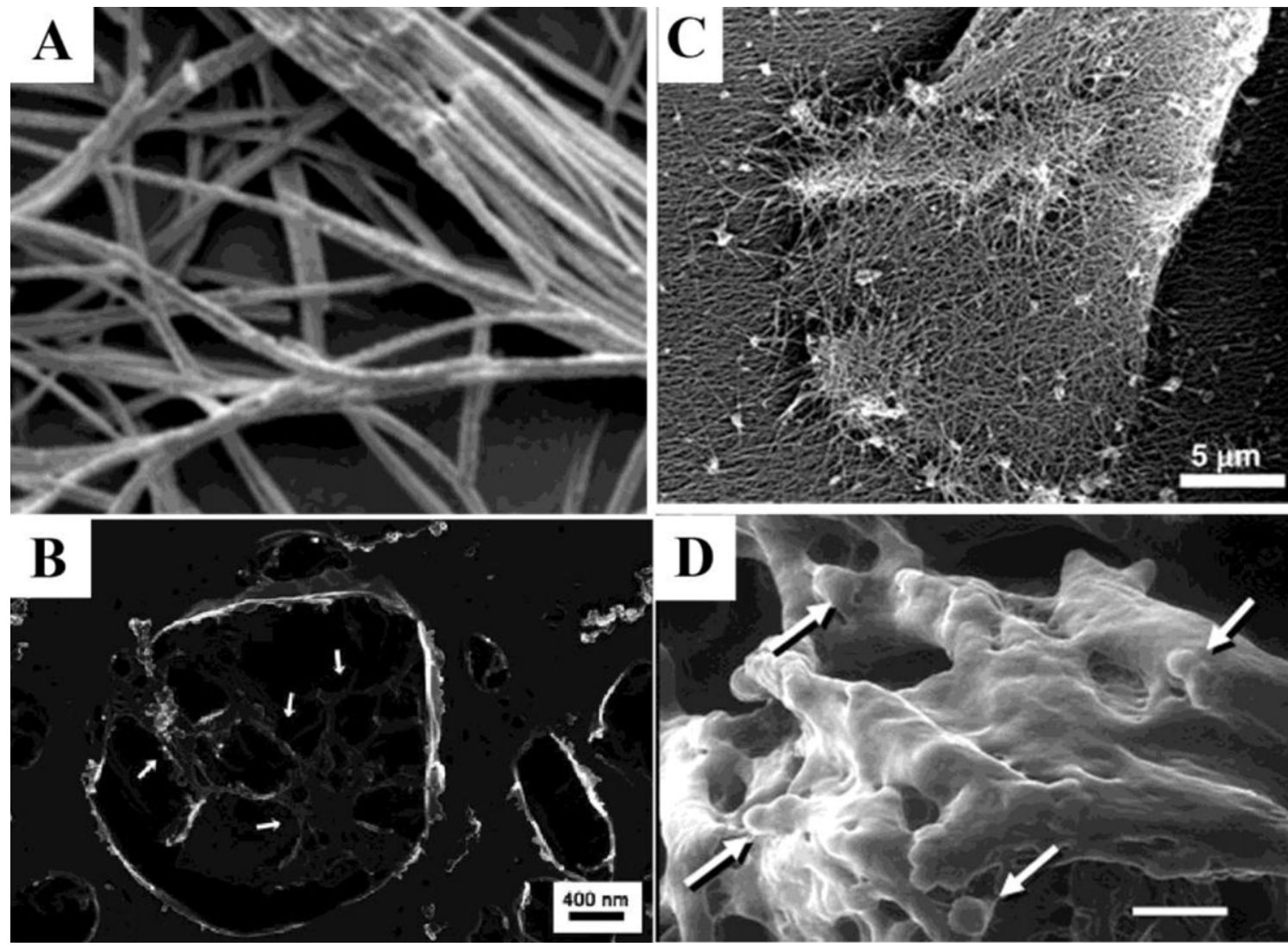

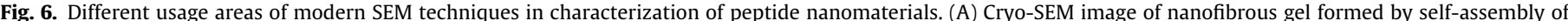

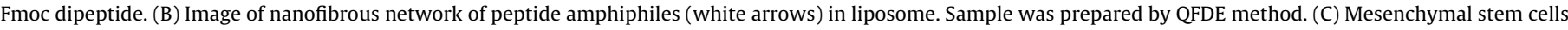
in PA nanofiber gel. Sample was prepared by fixation and critical point drying. (D) ESEM imaging of chondrocyte cells (white arrows) in Fmoc-dipeptide gel.

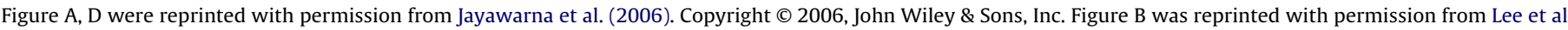

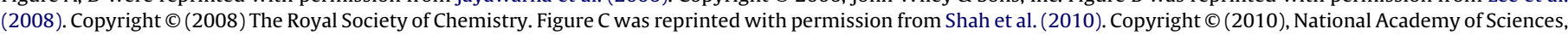
U.S.A.

A

$$
R=\operatorname{lin}_{0} \text { (B) }
$$$$
R=\gamma_{0}^{R}
$$

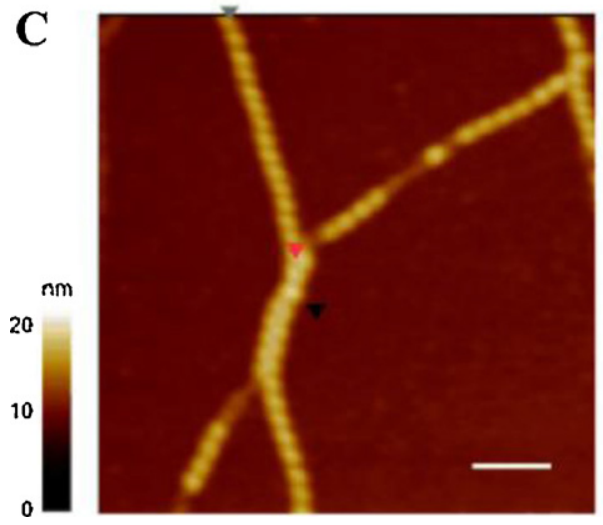

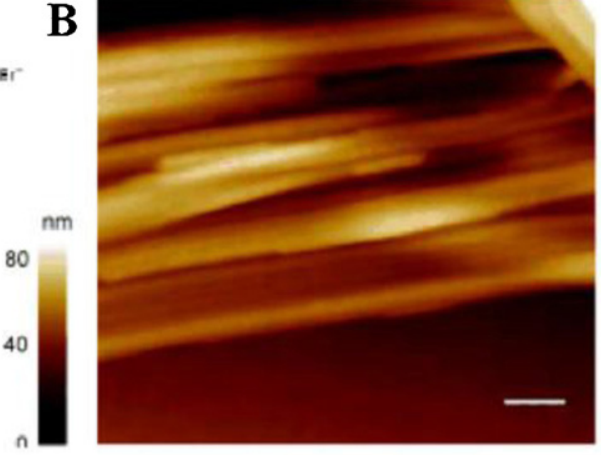

D

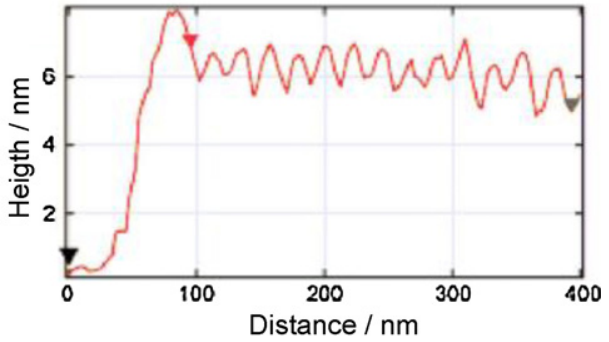

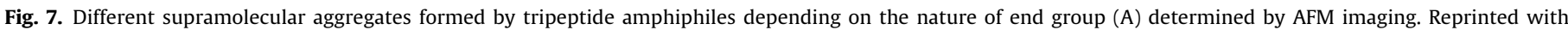

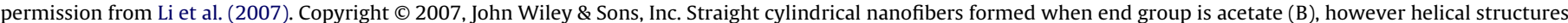
with regular pitch formed when bulkier end group is used such as dimethyl acetate (C and D). 
tures and measure pitch values between helices (Li et al., 2007; Muraoka et al., 2008). Tripeptide amphiphiles are found to form helical structures in organic solvents when the bulkier end group is used, most likely causing twisting of cylindrical nanostructures (Fig. 7A-C) (Li et al., 2007). Delicate observation of height profiles obtained by AFM indicated left handedness of helical structures (Fig. 7D). Moreover, pitch values obtained for different helical structures showed correlation with increased bulkiness of end group, suggesting torsional strain might be the mechanism for formation of these helices (Li et al., 2007).

Contact mode AFM is another choice for imaging peptide nanostructures. Since continual contact of AFM tip with surface might damage features on the surface, researchers use non-contact or tapping mode AFM for this purpose. However, by using soft contact mode, it is possible to get high resolution images without damaging organics on the surface. To achieve this, it is crucial to use AFM tips with low spring constant $(0.2 \mathrm{~N} / \mathrm{m}$ or below), which are appropriate for soft contact mode purposes. We have used contact mode to visualize different peptide amphiphile nanofibers and were able to obtain high resolution images (Toksoz et al., 2011).

Peptide nanostructures can also be visualized in solution, which is better to observe their native form by eliminating effects caused by sample drying. Imaging biological samples in native aqueous environment is a key advantage of AFM over other microscopy techniques. One of the main issues in wet imaging is immobilization of specimen to the surface. While tapping mode allows visualizing biological processes and molecules weakly adsorbed to the surface, due to minimization of lateral forces in this mode, immobilization is critical for contact mode imaging, where lateral forces of AFM tip may drift specimen (Engel and Muller, 2000). Two different types of immobilization are noncovalent and covalent methods. Noncovalent approach is more simple and based on physical adsorption of specimen onto surface through forces like van der Waals forces, electrostatic double-layer (EDL) forces, hydration forces and hydrophobic effects (Wagner, 1998). Chemical modification of surface can increase adsorption of molecules onto surface. For example, silanization of surface can help adhesion of biopolymers (Wagner, 1998). Covalently linking specimen to the surface becomes important when displacement of molecule on the surface is a critical problem. Limiting issue of immobilization technique is inactivation of the biological structure or process to be observed (Engel and Muller, 2000; Wagner, 1998). Surface energy, surface charges and hydrophobicity are properties to be considered for preservation of structures immobilized to surface. For example, hydrophobic surfaces are not recommended for wet imaging. Because, they interfere with AFM imaging due to increased adhesion and denaturation of proteins (Wagner, 1998).

Horii et al. (2007) imaged peptide nanofibers in aqueous solution by using tapping mode AFM, where observed size of nanofibers were greater than expected. It is acceptable to assume that nanofibers became hydrated in solution and observed size was greater than expected size.

Radius of the AFM tip is an important parameter for resolution, since tip convolution (also called as tip imaging) should be avoided in order to understand exact size and shape of observed feature on the surface. For this purpose, tip width should be smaller than width of structures on the surface. Otherwise, observed image will be affected by tip shape. It is better to use tips with radii smaller than $10 \mathrm{~nm}$ to observe fine nanostructures on the surface. Genove et al. used such AFM tips in order to visualize nanostructures on the surface. Samples were prepared with $0.01 \mathrm{wt} \%$ peptide solutions and observed by using tapping mode AFM (Genové et al., 2005). It is also possible to subtract convolution effects, by using mathematical models developed for sample-tip interaction. By assuming geometric shape of structures on the surface, it is possible to convert observed width to real width (Hong et al., 2003).
Atomic force microscopy imaging can yield high resolution images that can be used to study various conformations of biomolecules and their secondary structures. Scheuring et al. (2003) have carried out an extensive high-resolution study on Rhodobacter sphaeroides light harvesting complex 2, demonstrating the capability of force microscopy for topographic characterization of biomolecules with higher than $0.1 \mathrm{~nm}$ resolution. High-resolution imaging of biomolecules can be done by using dynamic AFM. San Paulo and García (2000) have shown the importance of choosing correct imaging parameters in obtaining artifact free images of antibodies with minimal sample damage.

Surface properties of substrate used in sample preparation might significantly affect quality of images obtained with AFM. Jiang et al. (2007) prepared the samples by dipping silicon wafer or gold surface into $0.1 \mathrm{wt} \%$ solution of PA and air-drying after slowly withdrawing them. Interestingly, they observed high-aspect-ratio cylindrical nanofibers on silicon surface, while significantly less linear features on gold surface, with less clear image (Fig. 8). Authors explained this by suggesting that surface roughness of gold surface probably interferes with AFM imaging. Surface properties might affect formation of nanostructures on the surface, especially if sample preparation method is based on air drying. To eliminate effects of surface on nanostructure formation, solutions should be coated onto different surfaces with varying chemical properties. For this purpose, Ashkenasy et al. (2006) used mica, highly oriented pyrolytic graphite (HOPG) and hydroxylated silicon oxide for visualizing nanotubes formed by cyclic peptides and imaged with tapping mode AFM. As authors observed similar nanotube structures on all materials, they concluded that nanotubes formed in solution, and not by interaction with material surface.

Besides giving topographical information about the analyzed surface, AFM can also provide information about the stiffness of surface nanostructures and the adhesion properties between peptides and a bare or functionalized AFM tip. Such nanomechanical mapping produces an elastic modulus map of the surface, including quantitative values for each feature on the surface (Sahin and Erina, 2008). Several established techniques exist for nanomechanical mapping (Heuberger et al., 1995; Maivald et al., 1991; Miyatani et al., 1997; Radmacher et al., 1993; RosaZeiser et al., 1997). However, organic molecules are typically fragile and measurements must be performed in a way that does not apply large forces and pressures during mapping (San Paulo and García, 2000). Recently, novel techniques that can produce nanomechanical maps with high resolution and minimal sample damage have been introduced (Dong et al., 2009; Husale et al., 2009). While, novel techniques continue to gain popularity, conventional force spectroscopy has been instrumental in nanomechanical characterization. Dagdas et al. (2011) used AFM to carry out force-distance measurements for identifying stiffness values of PA nanofibers. Authors used surfaces with known stiffness values (silicon and PMMA) to estimate and compare elastic moduli of PA nanofiber films made with calcium ions or $\mathrm{HCl}$. Elastic moduli of both nanofilms were $0.1 \pm 0.05 \mathrm{GPa}$, while one made with calcium had slightly higher stiffness (0.2 $\pm 0.1 \mathrm{GPa})$. Helen et al. (2011) also investigated the effect of gelation conditions on adhesion and stiffness of selfassembled organic materials and they used force-spectroscopy in liquid to correlate adhesion and stiffness properties to macroscopic mechanical properties. Smith et al. (2006) has applied force spectroscopy on amyloid fibrils self-assembled from insulin, by probing free standing fibrils on gold surfaces patterned with grooves. Such geometries are particularly suitable for quantitative analysis due to well defined boundary conditions, and Smith et al. extracted an elastic modulus of $3.3 \pm 0.4 \mathrm{GPa}$ and strength of $0.6 \pm 0.4 \mathrm{GPa}$. Adhesion is also an important parameter in understanding the mechanical and chemical properties of peptidic nanostructures. Horinek et al. (2008) used force-extension (pulling) data to inves- 

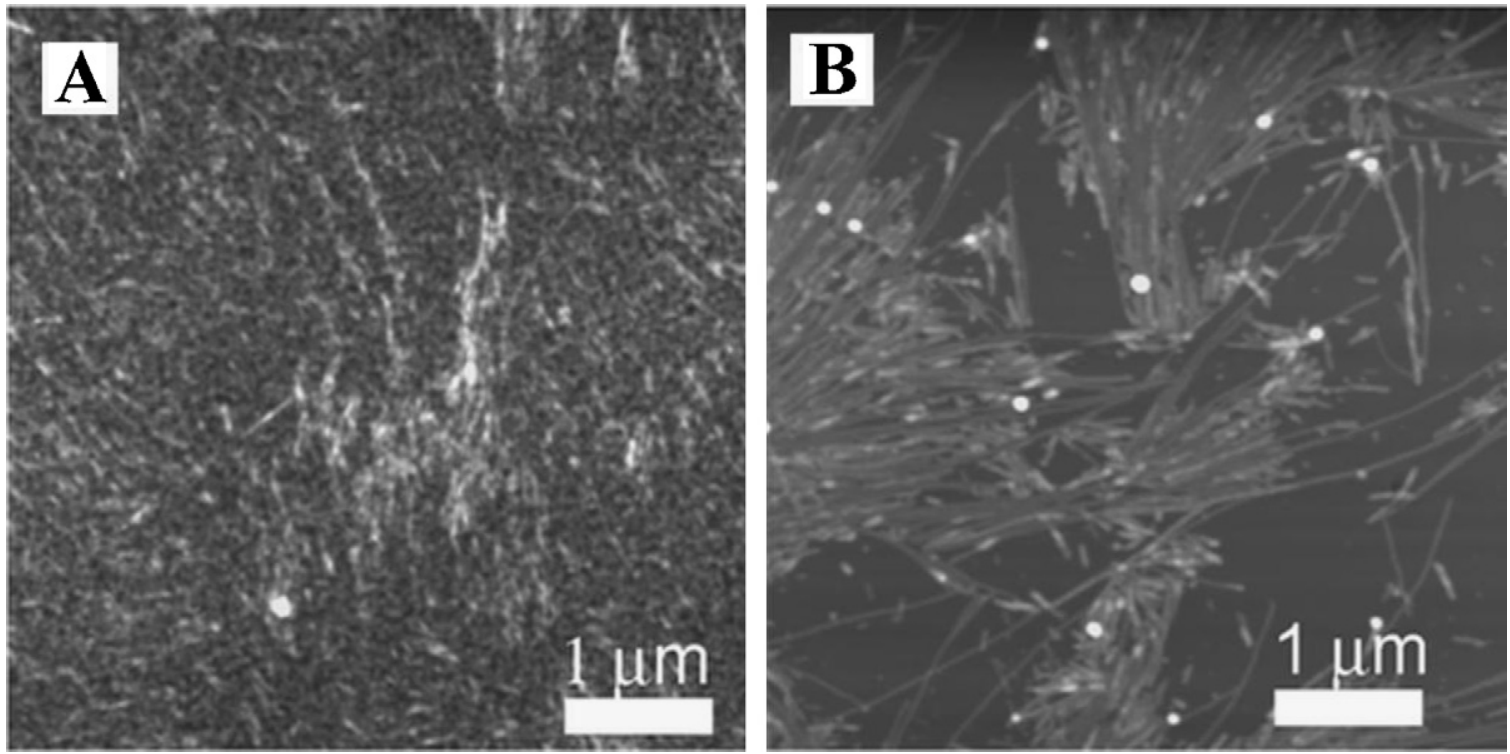

Fig. 8. AFM imaging of PA nanofibers formed on gold (A) and silicon (B) surface. Reprinted with permission from Jiang et al. (2007). Copyright @ (2007) The Royal Society of Chemistry.

tigate adsorption mechanism of peptides on hydrophobic surfaces, to find out that multiple mechanisms are responsible in determining the adsorption strength. The mechanical mapping can be performed both in air and in liquid, enabling study of various environments on mechanical and adhesion properties. Dong et al. has studied force-extension on self-assembled fibrils formed by 29residue amphiphatic peptide hormone glucagon in buffer with a $\mathrm{pH}$ of 2.0 (Mingdong et al., 2008). Kim et al. has used a functionalized tip to measure the binding properties of lipopolysaccharides (LPS) on immune proteins (lipopolysaccharide binding protein [LBP] and CD14). In their study, Kim et al. (2007) have directly observed the concentration dependent inhibitory effect of antimicrobial peptide, polymyxin $\mathrm{B}$ (PMB) on binding of LBP-LPS and CD14. In functionalized tip studies, typically a linker (or spacer) is used to affix biomolecules onto the tip. This allows free motion and conformation of the molecule on the tip. The effect of linker properties on adhesion properties have been studied previously (Craig et al., 2008), and it was found that optimal spacer lengths yielded highest adhesion, underlying the complex nature of such direct quantitative measurements. In nanomechanical mapping and adhesion studies, typically a large number of measurements are performed and data is analyzed using histograms to obtain statistically significant information about the sample. During nanomechanical measurements, for force-extension experiments typically soft cantilevers with spring constants on the order of $0.01-0.1 \mathrm{~N} / \mathrm{m}$ are used, while for elastic modulus measurements stiffer cantilevers $(1-10 \mathrm{~N} / \mathrm{m})$ are preferred.

AFM is a highly sophisticated technique, which can bring out high resolution images not only about three-dimensional topography of surface, but also mechanical properties of molecules on the surface. Besides this, laborious sample preparation techniques are not required in this method. All these make AFM very attractive for researchers working with peptide nanomaterials.

\section{Optical microscopy-based techniques}

Despite having lower resolution and magnification, several optical microscopy techniques such as polarizing, fluorescence and confocal microscopy provide invaluable information for characterization of peptide nanostructures. Immunostaining of samples provide excellent contrast for fine structures and allows obtaining images which cannot be obtained with TEM, SEM or AFM.

In polarizing microscopy, the sample is illuminated by polarized light, which interacts with anisotropic domains and generates contrast between anisotropic domains and other parts of material. Self-assembly of peptide molecules produce different liquid crystalline domains in gels. Polarizing light microscopy allowed identification of a unique optical property - birefringency - of these anisotropic domains. Hartgerink et al. (2002) showed orientation of liquid crystalline phase of peptide amphiphile gels in the range of tens of microns (Fig. 9A). Concentration dependent variation of birefringence property of peptide amphiphile gels has also been demonstrated (Hung and Stupp, 2007). Hexagonal liquid crystalline phase changes to nematic phase with weaker birefringent property as PA concentration decreases. Uniform and large (tens of millimeters) birefringent domains were observed in polarizing microscopy images of aligned monodomain PA gel films, where uniformity of birefringency indicated alignment of nanofibers to constitute gel film (Fig. 9B-D) (Zhang et al., 2010). Staining also stands to be a powerful method to detect peptide nanostructures in solution. Congo red dye, which binds to $\beta$-sheet-rich regions, is widely used to detect amyloid-like structures. Congo red-stained amyloid-like peptide coated surfaces show birefringent yellow-green domains (Gilead and Gazit, 2004).

Ordered assembly of nanostructures can give rise to higherorder structures, which can be observed even by light microscopy. For example, peptide nanotubes (based on diphenylalanine selfassembly) films formed on different surfaces such as gold, $\mathrm{SiO}_{2}$ and InP were imaged with optical microscopy along with other imaging techniques (Hendler et al., 2007). Peptide nanotube crystallization gave rise to well-organized spherulites, which were clearly observed at this magnification.

Immunostaining of nanostructures is another method for visualization under fluorescence microscope. Limiting step here is the lack of specific antibodies against peptide molecules forming the nanostructures. Amyloid nanofibrils are appropriate examples for this case since they are formed by aggregation of natural polypeptides. In one study, fibrils formed in drosophila brain by $\beta$ amyloid polypeptide, which plays a critical role in the pathology of neurodegenerative diseases such as Alzheimer's disease, were stained by using a specific antibody and observed under fluores- 

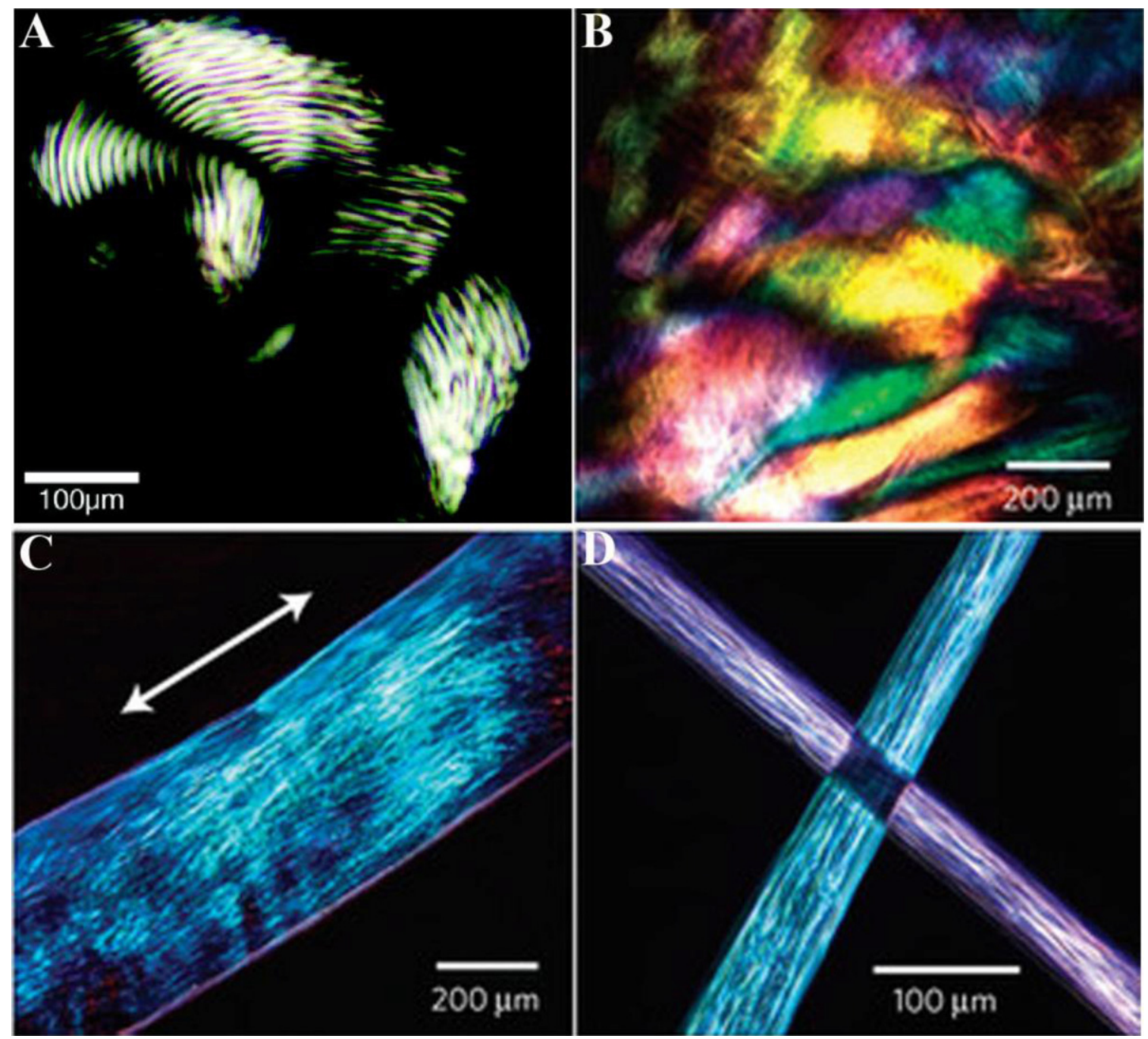

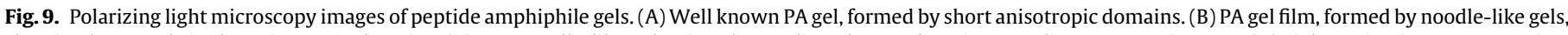

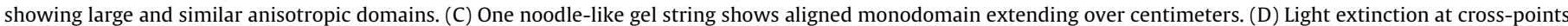
of two gel strings shows uniform alignment in each string.

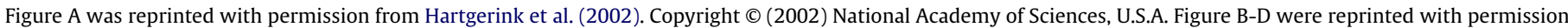
from Zhang et al. (2010). Copyright ( $)$ (2010) Macmillan Publishers Ltd.

cent microscope where self-assembled fibrillar structures stained with $\beta$-amyloid antibody could be observed (Scherzer-Attali et al., 2010). Filamentous temperature-sensitive protein $Z$ (FtsZ) is a prokaryotic monomeric protein (homologous to eukaryotic protein tubulin) which self-assembles into filamentous structures forming contractile ring or Z-ring. Formation of contractile ring is critical for prokaryotic cell division. Inspired by self-assembly of FtsZ molecules, Ostrov and Gazit (2010) synthesized nanowires, with these molecules. For this purpose, FtsZ proteins expressed in bacteria were tagged with gold-binding, silver-reducing or biotinylation motives at gene level. Biotinylated FtsZ polymers were stained with fluorescent avidin and imaged by confocal microscopy, which allowed observing fluorescently stained filamentous structures.

Peptide-based nanostructures can also be labeled covalently with fluorescent dyes for real-time imaging of dynamic processes. Kameta et al. labeled bolaamphiphiles with Alexa dye through amine groups and observed fluorescent nanotubes formed by these molecules. To investigate encapsulation and transportation of GFP in Alexa nanotubes, time-lapse fluorescence microscopy was used (Fig. 10A). Excitation and absorption filters used in mirror unit of microscope allowed detection of FRET (fluorescence resonance energy transfer) from GFP to Alexa, which occurs in nanotubes, while cutting bulk GFP fluorescence in solution and direct excitation of Alexa (Kameta et al., 2008).

Staining $\beta$-sheet-rich nanostructures with fluorescent dyes such as Thioflavin T (ThT) is another possibility for fluorescence imaging of peptide nanostructures. ThT binds to $\beta$-sheets in amyloid fibrils and gives a characteristic shift in its emission spectrum. Tamamis et al. (2009) stained triphenylalanine assemblies by using ThT and analyzed these samples with confocal microscopy which showed elongated fibrillar structures (Fig. 10B).

Fluorescent imaging also allows following each molecule in bulk gel, when latter one is formed by mixing two or more molecules such as heparin and heparin-binding PA. Fluorescent labeling of heparin allowed observing heparin in PA gel by using confocal microscopy (Fig. 10C) (Rajangam et al., 2006). Sometimes, chemical structures of some peptide molecules allow displaying photoluminescence property without further staining procedure. Diphenylalanine (FF) peptide nanotubes show photoluminescence in blue and UV regions of excitation origin caused by quantum confined phenomenon in these nanostructures (Amdursky 


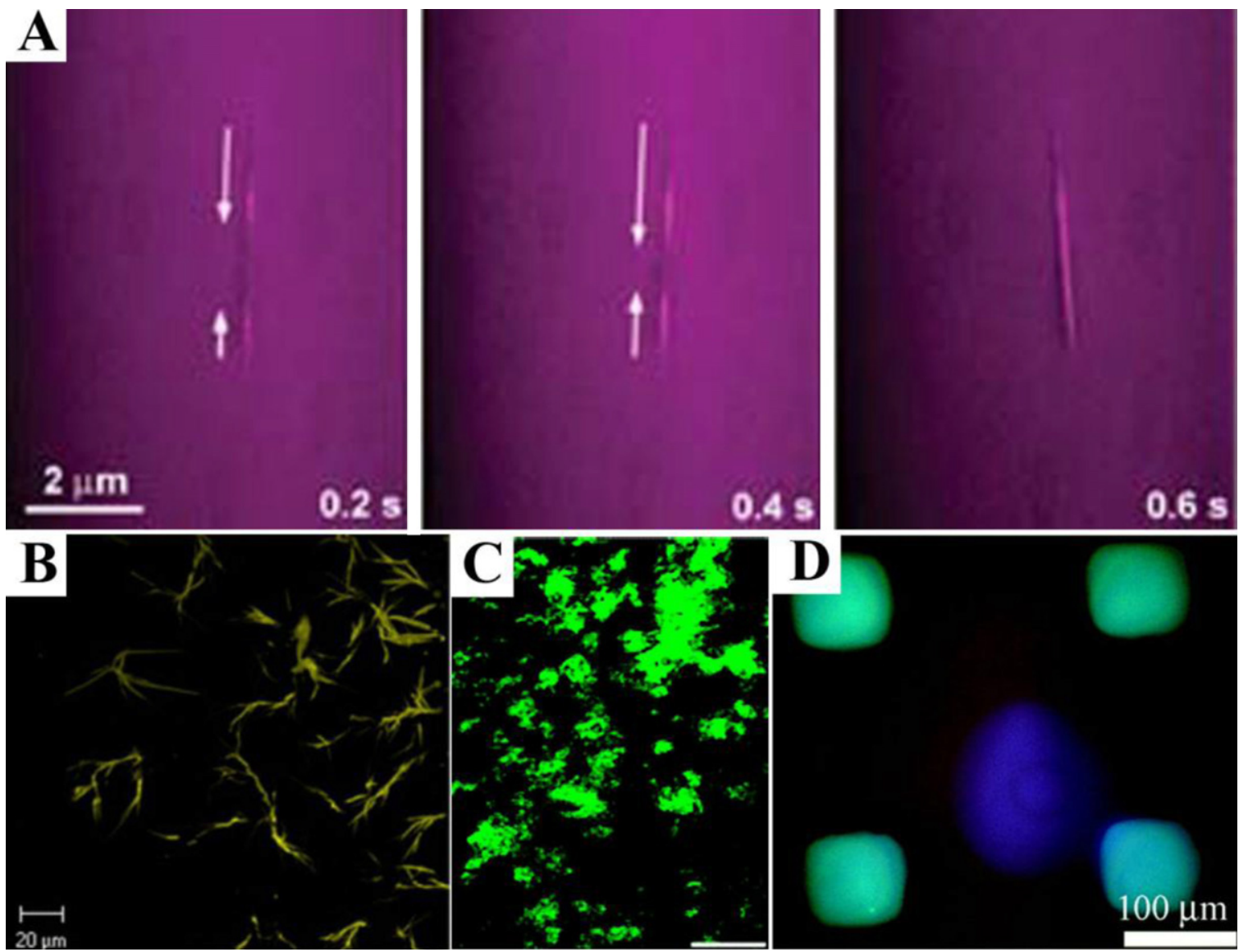

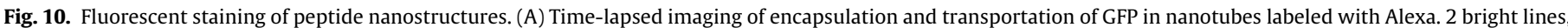

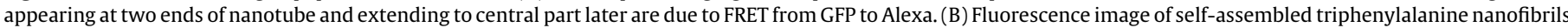

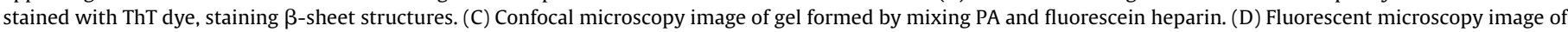

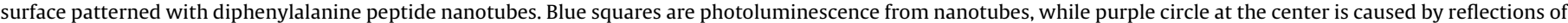
excitation beam from surface. (For interpretation of the references to color in this figure legend, the reader is referred to the web version of the article.)

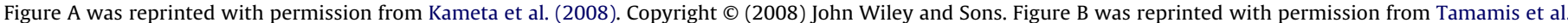

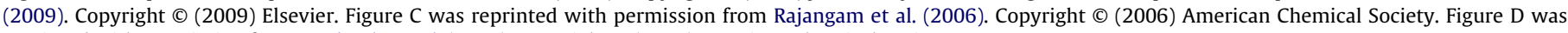
reprinted with permission from Amdursky et al. (2009). Copyright () (2009) American Chemical Society.

et al., 2009). Patterned surface with FF nanotubes showed fluorescence (excitation at $340-380 \mathrm{~nm}$ ) from expected regions (Fig. 10D).

FRET can be used to detect specific interactions in biomolecular and dynamic systems such as peptide amphiphile gels. In a co-assembly system comprised of fluorophore attached PA and non-fluorescent secondary PA, FRET was observed between donor - fluorescent PA and fluorophore carrying heparin - acceptor, which binds to non-fluorescent PA (Behanna et al., 2006). The energy transfer was verified by acceptor photobleaching experiment, which recovered emission from the donor.

Raman spectroscopy is another powerful technique to investigate the presence of various groups and their binding properties. Raman microscopy provides diffraction limited imaging of biomolecular structures and conventionally cannot provide single molecule resolution. Typically, the imaging volume is about a micrometer cube. Even though individual fibers cannot be resolved with confocal Raman microscopy, Matsui and Douberly (2001) demonstrated that Raman signatures can be used to identify bundles and individual nanotubes self-assembled out of the bolaamphiphilic peptide monomer bis(N-R-amidoglycylglycine)-1,7-heptane dicarboxylate. They have shown that Raman signatures can be used to discriminate peptidic nanostructures bound to the bundles and the peptide nanotubes disassembled from the bundle.
Tip and surface enhanced Raman spectroscopy (TERS and SERS) have been extensively used to characterize biomolecules as well. The versatility of the TERS method is demonstrated by Neugebauer et al. (2006) who collected location dependent Raman data on bacterial surfaces (S. epidermidis cells), showing peptidic Raman bands. Yeo et al. (2008) performed TERS on Cytochrome c (Cc), and demonstrated the superior performance of TERS method on resolving both the heme and amino acid vibrational bands. Deckert-Gaudig and Deckert (2010) demonstrated extremely high spatial resolution (nanometer) of TERS on insulin fibrils. TERS technique is typically applied with a combined Raman and AFM/STM system, whereas SERS can be performed using a simpler Raman spectrometer. Aliaga et al. (2011) have demonstrated that a large number of bands can be observed and identified using SERS with silver nanoparticles, on synthetic carboxy terminal peptide of human chorionic gonadatropin b-subunit. Reproducible SER Spectra were obtained by adding the colloidal AgNP solution onto the dried analyte sample. Simplicity of the SERS technique allows wide applicability compared to TERS, in applications not requiring spatial resolution.

Optical microscopy techniques take a snapshot of peptide nanostructures from a different aspect. These techniques should be used to identify specific domains or structures by labeling for fluorescence microscopy and FRET technique or by using specialized techniques such as polarizing microscopy and Raman-based microscopy. 


\section{Conclusion}

Peptide nanomaterials are promising candidates to solve many issues regarding health, energy and information technology. Progress in this field benefits immensely from characterization studies performed by highly advanced microscopes. Capabilities of each microscopy technique allow investigation of nanomaterials from different aspects. TEM imaging, which relies on electrons travelling inside the sample, allows identifying ultrafine patterns on nanostructures. On the other hand, SEM imaging gets information from electrons scattered on the surface of the sample, so it is advantageous for imaging thicker and bulkier samples. AFM can provide topographical and mechanical view of the surface, with an easier sample preparation protocol. Optical microscopy techniques, in spite of lower resolution, provide very useful information such as identification of anisotropic domains in peptide gel with polarizing light microscopy. It is important for researchers who work in this area to understand limitations and advantages of each microscopy technique and choose the right one for characterization studies.

\section{References}

Acar, H., Garifullin, R., Guler, M.O., 2011. Self-assembled template-directed synthesis of one-dimensional silica and titania nanostructures. Langmuir 27, 1079-1084. Adler-Abramovich, L., Badihi-Mossberg, M., Gazit, E., Rishpon, J., 2010. Characterization of peptide-nanostructure-modified electrodes and their application for ultrasensitive environmental monitoring. Small 6, 825-831.

Adler-Abramovich, L., Reches, M., Sedman, V.L., Allen, S., Tendler, S.J.B., Gazit, E., 2006. Thermal and chemical stability of diphenylalanine peptide nanotubes: implications for nanotechnological applications. Langmuir 22, 1313-1320.

Alessandrini, A., Facci, P., 2005. AFM: a versatile tool in biophysics. Meas. Sci. Technol. 16, R65-R92.

Aliaga, A.E., Aguayo, T., Garrido, C., Clavijo, E., Hevia, E., Gómez-Jeria, J.S., Leyton, P., Campos-Vallette, M.M., Sanchez-Cortes, S., 2011. Surface-enhanced Raman scattering and theoretical studies of the C-terminal peptide of the $\beta$-subunit human chorionic gonadotropin without linked carbohydrates. Biopolymers 95, $135-143$.

Allison, D.P., Mortensen, N.P., Sullivan, C.J., Doktycz, M.J., 2010. Atomic force microscopy of biological samples. Wiley Interdiscip. Rev.: Nanomed. Nanobiotechnol. 2, 618-634.

Amdursky, N., Molotskii, M., Aronov, D., Adler-Abramovich, L., Gazit, E., Rosenman, G., 2009. Blue luminescence based on quantum confinement at peptide nanotubes. Nano Lett. 9, 3111-3115.

Ashkenasy, N., Horne, W.S., Ghadiri, M.R., 2006. Design of self-assembling peptide nanotubes with delocalized electronic states. Small 2, 99-102.

Aulisa, L., Forraz, N., McGuckin, C., Hartgerink, J.D., 2009. Inhibition of cancer cell proliferation by designed peptide amphiphiles. Acta Biomater. 5, 842-853.

Banerjee, I.A., Yu, L., Matsui, H., 2003. Cu nanocrystal growth on peptide nanotubes by biomineralization: size control of $\mathrm{Cu}$ nanocrystals by tuning peptide conformation. Proc. Natl. Acad. Sci. U.S.A. 100, 14678-14682.

Behanna, H.A., Rajangam, K., Stupp, S.I., 2006. Modulation of fluorescence through coassembly of molecules in organic nanostructures. J. Am. Chem. Soc. 129, 321-327.

Beniash, E., Hartgerink, J.D., Storrie, H., Stendahl, J.C., Stupp, S.I., 2005. Selfassembling peptide amphiphile nanofiber matrices for cell entrapment. Acta Biomater. 1, 387-397.

Bull, S.R., Guler, M.O., Bras, R.E., Meade, T.J., Stupp, S.I., 2005. Self-assembled peptide amphiphile nanofibers conjugated to MRI contrast agents. Nano Lett. 5, 1-4.

Bull, S.R., Palmer, L.C., Fry, N.J., Greenfield, M.A., Messmore, B.W., Meade, T.J., Stupp, S.I., 2008. A templating approach for monodisperse self-assembled organic nanostructures. J. Am. Chem. Soc. 130, 2742-2743.

Capito, R.M., Azevedo, H.S., Velichko, Y.S., Mata, A., Stupp, S.I., 2008. Self-assembly of large and small molecules into hierarchically ordered sacs and membranes. Science $319,1812-1816$

Carny, O., Shalev, D.E., Gazit, E., 2006. Fabrication of coaxial metal nanocables using a self-assembled peptide nanotube scaffold. Nano Lett. 6, 1594-1597.

Chow, L.W., Bitton, R., Webber, M.J., Carvajal, D., Shull, K.R., Sharma, A.K., Stupp, S.I., 2011. A bioactive self-assembled membrane to promote angiogenesis. Biomaterials 32, 1574-1582.

Chow, L.W., Wang, L.J., Kaufman, D.B., Stupp, S.I., 2010. Self-assembling nanostructures to deliver angiogenic factors to pancreatic islets. Biomaterials 31 , 6154-6161.

Claussen, R.C., Rabatic, B.M., Stupp, S.I., 2003. Aqueous self-assembly of unsymmetric peptide bolaamphiphiles into nanofibers with hydrophilic cores and surfaces. J. Am. Chem. Soc. 125, 12680-12681.

Cohen, T., Frydman-Marom, A., Rechter, M., Gazit, E., 2006. Inhibition of amyloid fibril formation and cytotoxicity by hydroxyindole derivatives. Biochemistry 45 , 4727-4735.
Craig, J.A., Rexeisen, E.L., Mardilovich, A., Shroff, K., Kokkoli, E., 2008. Effect of linker and spacer on the design of a fibronectin-mimetic peptide evaluated via cell studies and AFM adhesion forces. Langmuir 24, 10282-10292.

Cui, H., Muraoka, T., Cheetham, A.G., Stupp, S.I., 2009. Self-assembly of giant peptide nanobelts. Nano Lett. 9, 945-951.

Cui, H., Webber, M.J., Stupp, S.I., 2010. Self-assembly of peptide amphiphiles: from molecules to nanostructures to biomaterials. Peptide Sci. 94, 1-18.

Dagdas, Y.S., Tombuloglu, A., Tekinay, A.B., Dana, A., Guler, M.O., 2011. Interfiber interactions alter the stiffness of gels formed by supramolecular self-assembled nanofibers. Soft Matter 7, 3524-3532.

Deckert-Gaudig, T., Deckert, V., 2010. Tip-enhanced Raman scattering (TERS) and high-resolution bio nano-analysis-a comparison. Phys. Chem. Chem. Phys. 12 12040-12049.

Dolphin, G.T., Dumy, P., Garcia, J., 2006. Control of amyloid beta-peptide protofibril formation by a designed template assembly. Angew. Chem. Int. Ed. 45, 2699-2702.

Dong, M.D., Husale, S., Sahin, O., 2009. Determination of protein structural flexibility by microsecond force spectroscopy. Nat. Nanotechnol. 4, 514-517.

Dvir, T., Timko, B.P., Kohane, D.S., Langer, R., 2011. Nanotechnological strategies for engineering complex tissues. Nat. Nanotechnol. 6, 13-22.

Egerton, R.F., 2005. Physical Principles of Electron Microscopy: An Introduction to TEM, SEM, and AEM. Springer, New York, NY.

Engel, A., Lyubchenko, Y., Müller, D., 1999. Atomic force microscopy: a powerful too to observe biomolecules at work. Trends Cell Biol. 9, 77-80.

Engel, A., Muller, D.J., 2000. Observing single biomolecules at work with the atomic force microscope. Nat. Struct. Biol. 7, 715-718.

Farokhzad, O.C., Langer, R., 2009. Impact of nanotechnology on drug delivery. ACS Nano $3,16-20$

Fotiadis, D., Scheuring, S., Müller, S.A., Engel, A., Müller, D.J., 2002. Imaging and manipulation of biological structures with the AFM. Micron 33, 385-397.

Gazit, E., 2007. Self-assembled peptide nanostructures: the design of molecular building blocks and their technological utilization. Chem. Soc. Rev. 36, 1263-1269

Gelain, F., Bottai, D., Vescovi, A., Zhang, S., 2006. Designer self-assembling peptide nanofiber scaffolds for adult mouse neural stem cell 3-dimensional cultures. PLoS One 1, e119.

Genové, E., Shen, C., Zhang, S., Semino, C.E., 2005. The effect of functionalized self-assembling peptide scaffolds on human aortic endothelial cell function. Biomaterials 26, 3341-3351.

Gilead, S., Gazit, E., 2004. Inhibition of amyloid fibril formation by peptide analogues modified with $\alpha$-aminoisobutyric acid. Angew. Chem. Int. Ed. 43 4041-4044.

Guler, M.O., Hsu, L., Soukasene, S., Harrington, D.A., Hulvat, J.F., Stupp, S.I., 2006. Presentation of RGDS epitopes on self-assembled nanofibers of branched peptide amphiphiles. Biomacromolecules 7, 1855-1863.

Guler, M.O., Soukasene, S., Hulvat, J.F., Stupp, S.I., 2005. Presentation and recognition of biotin on nanofibers formed by branched peptide amphiphiles. Nano Lett. 5 249-252.

Guler, M.O., Stupp, S.I., 2007. A self-assembled nanofiber catalyst for ester hydrolysis J. Am. Chem. Soc. 129, 12082-12083.

Hartgerink, J.D., Beniash, E., Stupp, S.I., 2001. Self-assembly and mineralization of peptide-amphiphile nanofibers. Science 294, 1684-1688.

Hartgerink, J.D., Beniash, E., Stupp, S.I., 2002. Peptide-amphiphile nanofibers: a versatile scaffold for the preparation of self-assembling materials. Proc. Natl. Acad. Sci. U.S.A. 99, 5133-5138.

Helen, W., de Leonardis, P., Ulijn, R.V., Gough, J., Tirelli, N., 2011. Mechanosensitive peptide gelation: mode of agitation controls mechanical properties and nanoscale morphology. Soft Matter 7, 1732-1740.

Hendler, N., Sidelman, N., Reches, M., Gazit, E., Rosenberg, Y., Richter, S., 2007. Formation of well-organized self-assembled films from peptide nanotubes. Adv. Mater. 19, 1485-1488.

Heuberger, M., Dietler, G., Schlapbach, L., 1995. Mapping the local youngs modulus by analysis of the elastic deformations occurring in atomic-force microscopy. Nanotechnology 6, 12-23.

Hong, Y., Legge, R.L., Zhang, S., Chen, P., 2003. Effect of amino acid sequence and ph on nanofiber formation of self-assembling peptides EAK16-II and EAK16-IV. Biomacromolecules 4, 1433-1442.

Horii, A., Wang, X., Gelain, F., Zhang, S., 2007. Biological designer self-assembling peptide nanofiber scaffolds significantly enhance osteoblast proliferation, differentiation and 3-D migration. PLoS One 2, e190.

Horinek, D., Serr, A., Geisler, M., Pirzer, T., Slotta, U., Lud, S.Q., Garrido, J.A., Scheibel, T., Hugel, T., Netz, R.R., 2008. Peptide adsorption on a hydrophobic surface results from an interplay of solvation, surface, and intrapeptide forces. Proc. Natl. Acad. Sci. U.S.A. 105, 2842-2847.

Hsu, L., Cvetanovich, G.L., Stupp, S.I., 2008. Peptide amphiphile nanofibers with conjugated polydiacetylene backbones in their core. J. Am. Chem. Soc. 130 3892-3899.

Huang, Z., Sargeant, T.D., Hulvat, J.F., Mata, A., Bringas, P., Koh, C.-Y., Stupp, S.I., Snead, M.L., 2008. Bioactive nanofibers instruct cells to proliferate and differentiate during enamel regeneration. J. Bone Miner. Res. 23, 1995-2006.

Hung, A.M., Stupp, S.I., 2007. Simultaneous self-assembly, orientation, and patterning of peptide-amphiphile nanofibers by soft lithography. Nano Lett. 7 , 1165-1171.

Husale, S., Persson, H.H.J., Sahin, O., 2009. DNA nanomechanics allows direct digital detection of complementary DNA and microRNA targets. Nature 462 1075-1138. 
Jayawarna, V., Ali, M., Jowitt, T.A., Miller, A.E., Saiani, A., Gough, J.E., Ulijn, R.V., 2006. Nanostructured hydrogels for three-dimensional cell culture through selfassembly of fluorenylmethoxycarbonyl-dipeptides. Adv. Mater. 18, 611-614.

Jiang, H., Guler, M.O., Stupp, S.I., 2007. The internal structure of self-assembled peptide amphiphiles nanofibers. Soft Matter 3, 454-462.

Kameta, N., Masuda, M., Mizuno, G., Morii, N., Shimizu, T., 2008. Supramolecular nanotube endo sensing for a guest protein. Small 4, 561-565.

Kasotakis, E., Mossou, E., Adler-Abramovich, L., Mitchell, E.P., Forsyth, V.T., Gazit E., Mitraki, A., 2009. Design of metal-binding sites onto self-assembled peptide fibrils. Biopolymers 92, 164-172.

Kim, J.S., Jang, S., Kim, U., Cho, K., 2007. AFM studies of inhibition effect in binding of antimicrobial peptide and immune proteins. Langmuir 23, 1043810440 .

Kogiso, M., Okada, Y., Hanada, T., Yase, K., Shimizu, T., 2000. Self-assembled peptide fibers from valylvaline bola-amphiphiles by a parallel [beta]-sheet network. Biochim. Biophys. Acta (BBA)-Gen. Subjects 1475, 346-352.

Kohl, H., Reimer, L., SpringerLink (Online service), 2008. Transmission Electron Microscopy Physics of Image Formation, Springer Series in Optical Sciences. Springer-Verlag, New York, NY.

Lee, H.K., Soukasene, S., Jiang, H., Zhang, S., Feng, W., Stupp, S.I., 2008. Light-induced self-assembly of nanofibers inside liposomes. Soft Matter 4, 962-964.

Li, L.-S., Jiang, H., Messmore, B.W., Bull, S.R., Stupp, S.I., 2007. A torsional strain mechanism to tune pitch in supramolecular helices. Angew. Chem. Int. Ed. 46 5873-5876.

Lim, Y.B., Kwon, O.J., Lee, E., Kim, P.H., Yun, C.O., Lee, M., 2008. A cyclic RGD-coated peptide nanoribbon as a selective intracellular nanocarrier. Org. Biomol. Chem. 6, 1944-1948.

Liu, L., Xu, K., Wang, H., Tan, P.K., Fan, W., Venkatraman, S.S., Li, L., Yang, Y.Y. 2009. Self-assembled cationic peptide nanoparticles as an efficient antimicrobial agent. Nat. Nanotechnol. 4, 457-463.

Lutolf, M.P., Hubbell, J.A., 2005. Synthetic biomaterials as instructive extracellular microenvironments for morphogenesis in tissue engineering. Nat. Biotechnol. 23, 47-55.

Mahler, A., Reches, M., Rechter, M., Cohen, S., Gazit, E., 2006. Rigid, selfassembled hydrogel composed of a modified aromatic dipeptide. Adv. Mater. $18,1365-1370$

Maivald, P., et al., 1991. Using force modulation to image surface elasticities with the atomic force microscope. Nanotechnology 2, 103.

Mata, A., Geng, Y., Henrikson, K.J., Aparicio, C., Stock, S.R., Satcher, R.L., Stupp, S.I. 2010. Bone regeneration mediated by biomimetic mineralization of a nanofibe matrix. Biomaterials 31, 6004-6012.

Matsui, H., Douberly, G.E., 2001. Organization of peptide nanotubes into macroscopic bundles. Langmuir 17, 7918-7922.

Matsui, H., MacCuspie, R., 2001. Metalloporphyrin nanotube fabrication using peptide nanotubes as templates. Nano Lett. 1, 671-675.

Matsui, H., Pan, S., Gologan, B., Jonas, S.H., 2000. Bolaamphiphile nanotubetemplated metallized wires. J. Phys. Chem. B 104, 9576-9579.

Mingdong, D., et al., 2008. AFM-based force spectroscopy measurements of mature amyloid fibrils of the peptide glucagon. Nanotechnology 19, 384013.

Mishra, A., Panda, J.J., Basu, A., Chauhan, V.S., 2008. Nanovesicles based on self-assembly of conformationally constrained aromatic residue containing amphiphilic dipeptides. Langmuir 24, 4571-4576.

Miyatani, T., Horii, M., Rosa, A., Fujihira, M., Marti, O., 1997. Mapping of electrical double-layer force between tip and sample surfaces in water with pulsed-forcemode atomic force microscopy. Appl. Phys. Lett. 71, 2632-2634.

Muraoka, T., Cui, H.,Stupp, S.I., 2008. Quadruple helix formation of a photoresponsive peptide amphiphile and its light-triggered dissociation into single fibers. J. Am. Chem. Soc. 130, 2946-2947.

Muraoka, T., Koh, C.-Y., Cui, H., Stupp, S.I., 2009. Light-triggered bioactivity in three dimensions. Angew. Chem. Int. Ed. 48, 5946-5949.

Neugebauer, U., Rösch, P., Schmitt, M., Popp, J., Julien, C., Rasmussen, A., Budich, C., Deckert, V., 2006. On the way to nanometer-sized information of the bacteria surface by tip-enhanced raman spectroscopy. ChemPhysChem 7, 1428-1430.

Ostrov, N., Gazit, E., 2010. Genetic engineering of biomolecular scaffolds for the fabrication of organic and metallic nanowires. Angew. Chem. Int. Ed. 49, 3018-3021.

Pashuck, E.T., Cui, H., Stupp, S.I., 2010. Tuning supramolecular rigidity of peptide fibers through molecular structure. J. Am. Chem. Soc. 132, 6041-6046.

Pashuck, E.T., Stupp, S.I., 2010. Direct observation of morphological transformation from twisted ribbons into helical ribbons. J. Am. Chem. Soc. 132, 8819-8821.

Pease, R.F.W., 2008. Significant advances in scanning electron microscopes (1965-2007). Adv. Imag. Elect. Phys. 150, 53-86.

Piner, R.D., Zhu, J., Xu, F., Hong, S., Mirkin, C.A., 1999. “Dip-Pen” nanolithography. Science 283, 661-663.

Qiu, F., Chen, Y., Tang, C., Zhou, Q., Wang, C., Shi, Y.-K., Zhao, X., 2008. De novo design of a bolaamphiphilic peptide with only natural amino acids. Macromol. Biosci. 8, 1053-1059.

Radmacher, M., Tillmann, R.W., Gaub, H.E., 1993. Imaging viscoelasticity by force modulation with the atomic force microscope. Biophys. J. 64, 735-742.

Rajangam, K., Arnold, M.S., Rocco, M.A., Stupp, S.I., 2008. Peptide amphiphile nanostructure-heparin interactions and their relationship to bioactivity. Biomaterials 29, 3298-3305.

Rajangam, K., Behanna, H.A., Hui, M.J., Han, X., Hulvat, J.F., Lomasney, J.W., Stupp, S.I., 2006. Heparin binding nanostructures to promote growth of blood vessels. Nano Lett. 6, 2086-2090.

Reches, M., Gazit, E., 2003. Casting metal nanowires within discrete self-assembled peptide nanotubes. Science 300, 625-627.
Rele, S., Song, Y., Apkarian, R.P., Qu, Z., Conticello, V.P., Chaikof, E.L., 2007 D-periodic collagen-mimetic microfibers. J. Am. Chem. Soc. 129, 1478014787.

RosaZeiser, A., Weilandt, E., Hild, S., Marti, O., 1997. The simultaneous measurement of elastic, electrostatic and adhesive properties by scanning force microscopy: pulsed-force mode operation. Meas. Sci. Technol. 8, 1333-1338.

Ryadnov, M.G., Ceyhan, B., Niemeyer, C.M., Woolfson, D.N., 2003. "Belt and braces": a peptide-based linker system of de novo design. J. Am. Chem. Soc. 125, 9388-9394.

Ryadnov, M.G., Woolfson, D.N., 2003. Introducing branches into a self-assembling peptide fiber. Angew. Chem. Int. Ed. 42, 3021-3023.

Sahin, O., Erina, N., 2008. High-resolution and large dynamic range nanomechanical mapping in tapping-mode atomic force microscopy. Nanotechnology, 19.

Sahin, O., Magonov, S., Su, C., Quate, C.F., Solgaard, O., 2007. An atomic force microscope tip designed to measure time-varying nanomechanical forces. Nat. Nanotechnol. 2, 507-514.

San Paulo, A., García, R., 2000. High-resolution imaging of antibodies by tappingmode atomic force microscopy: attractive and repulsive tip-sample interaction regimes. Biophys. J. 78, 1599-1605.

Sargeant, T.D., Guler, M.O., Oppenheimer, S.M., Mata, A., Satcher, R.L., Dunand D.C., Stupp, S.I., 2008a. Hybrid bone implants: self-assembly of peptide amphiphile nanofibers within porous titanium. Biomaterials 29, 161171.

Sargeant, T.D., Rao, M.S., Koh, C.Y., Stupp, S.I., 2008b. Covalent functionalization of NiTi surfaces with bioactive peptide amphiphile nanofibers. Biomaterials 29 , 1085-1098.

Sarikaya, M., Tamerler, C., Jen, A.K.Y., Schulten, K., Baneyx, F., 2003. Molecular biomimetics: nanotechnology through biology. Nat. Mater. 2, 577585.

Scheibel, T., Parthasarathy, R., Sawicki, G., Lin, X.M., Jaeger, H., Lindquist, S.L., 2003. Conducting nanowires built by controlled self-assembly of amyloid fibers and selective metal deposition. Proc. Natl. Acad. Sci. U.S.A. 100, 4527 4532.

Scherzer-Attali, R., Pellarin, R., Convertino, M., Frydman-Marom, A., Egoz-Matia N., Peled, S., Levy-Sakin, M., Shalev, D.E., Caflisch, A., Gazit, E., Segal, D., 2010. Complete phenotypic recovery of an Alzheimer's disease model by a quinonetryptophan hybrid aggregation inhibitor. PLoS One 5, e11101.

Scheuring, S., Seguin, J., Marco, S., Lévy, D., Breyton, C., Robert, B., Rigaud, J.-L., 2003 AFM characterization of tilt and intrinsic flexibility of Rhodobacter sphaeroides light harvesting complex 2 (LH2). J. Mol. Biol. 325, 569-580.

Schneider, A., Garlick, J.A., Egles, C., 2008. Self-assembling peptide nanofiber scaffolds accelerate wound healing. PLoS One 3, e1410.

Schneider, J.P., Pochan, D.J., Ozbas, B., Rajagopal, K., Pakstis, L., Kretsinger, J., 2002. Responsive hydrogels from the intramolecular folding and self-assembly of a designed peptide. J. Am. Chem. Soc. 124, 15030-15037.

Shah, R.N., Shah, N.A., Del Rosario Lim, M.M., Hsieh, C., Nuber, G., Stupp, S.I., 2010 Supramolecular design of self-assembling nanofibers for cartilage regeneration. Proc. Natl. Acad. Sci. U.S.A. 107, 3293-3298.

Silva, G.A., Czeisler, C., Niece, K.L., Beniash, E., Harrington, D.A., Kessler, J.A., Stupp, S.I., 2004. Selective differentiation of neural progenitor cells by high-epitope density nanofibers. Science 303, 1352-1355.

Smeenk, J.M., Otten, M.B., Thies, J., Tirrell, D.A., Stunnenberg, H.G., van Hest, J.C. 2005. Controlled assembly of macromolecular beta-sheet fibrils. Angew. Chem. Int. Ed. 44, 1968-1971.

Smith, J.F., Knowles, T.P.J., Dobson, C.M., MacPhee, C.E., Welland, M.E., 2006. Characterization of the nanoscale properties of individual amyloid fibrils. Proc. Natl. Acad. Sci. U.S.A. 103, 15806-15811.

Sone, E.D., Stupp, S.I., 2004. Semiconductor-encapsulated peptide-amphiphile nanofibers. J. Am. Chem. Soc. 126, 12756-12757.

Spoerke, E.D., Anthony, S.G., Stupp, S.I., 2009. Enzyme directed templating of artificial bone mineral. Adv. Mater. 21, 425-430.

Standley, S.M., Toft, D.J., Cheng, H., Soukasene, S., Chen, J., Raja, S.M., Band, V., Band, H., Cryns, V.L., Stupp, S.I., 2010. Induction of cancer cell death by selfassembling nanostructures incorporating a cytotoxic peptide. Cancer Res. 70 3020-3026

Stone, D.A., Hsu, L., Stupp, S.I., 2009. Self-assembling quinquethiopheneoligopeptide hydrogelators. Soft Matter 5, 1990-1993.

Stupp, S.I., 2010. Self-assembly and biomaterials. Nano Lett. 10, 4783-4786.

Tamamis, P., Adler-Abramovich, L., Reches, M., Marshall, K., Sikorski, P., Serpell, L., Gazit, E., Archontis, G., 2009. Self-assembly of phenylalanine oligopeptides: insights from experiments and simulations. Biophys. J. 96, 5020-5029.

Tetard, L., Passian, A., Venmar, K.T., Lynch, R.M., Voy, B.H., Shekhawat, G., Dravid, V.P., Thundat, T., 2008. Imaging nanoparticles in cells by nanomechanical holography. Nat. Nanotechnol. 3, 501-505.

Toksoz, S., Acar, H., Guler, M.O., 2010. Self-assembled one-dimensional soft nanostructures. Soft Matter 6, 5839-5849.

Toksöz, S., Guler, M.O., 2009. Self-assembled peptidic nanostructures. Nano Today $4,458-469$.

Toksoz, S., Mammadov, R., Tekinay, A.B., Guler, M.O., 2011. Electrostatic effects on nanofiber formation of self-assembling peptide amphiphiles. J. Colloid Interface Sci. 356, 131-137.

Tsai, W.-W., Li, L.-S., Cui, H., Jiang, H., Stupp, S.I., 2008. Self-assembly of amphiphiles with terthiophene and tripeptide segments into helical nanostructures. Tetrahedron 64, 8504-8514.

Tysseling-Mattiace, V.M., Sahni, V., Niece, K.L., Birch, D., Czeisler, C., Fehlings, M.G., Stupp, S.I., Kessler, J.A., 2008. Self-assembling nanofibers inhibit glial scar 
formation and promote axon elongation after spinal cord injury. J. Neurosci. 28, 3814-3823.

Ulijn, R.V., Smith, A.M., 2008. Designing peptide based nanomaterials. Chem. Soc. Rev. 37, 664-675.

Urban, K.W., 2008. Studying atomic structures by aberration-corrected transmission electron microscopy. Science 321, 506-510.

Vernon-Parry, K.D., 2000. Scanning electron microscopy: an introduction. III-Vs Review 13, 40-44.

Wagner, P., 1998. Immobilization strategies for biological scanning probe microscopy. FEBS Lett. 430, 112-115.

Webber, M.J., Kessler, J.A., Stupp, S.I., 2010. Emerging peptide nanomedicine to regenerate tissues and organs. J. Intern. Med. 267, 71-88.

$\mathrm{Xu}, \mathrm{C}$., Kopecek, J., 2008. Genetically engineered block copolymers: influence of the length and structure of the coiled-coil blocks on hydrogel self-assembly. Pharm. Res. 25, 674-682.
Yeo, B.-S., Madler, S., Schmid, T., Zhang, W., Zenobi, R., 2008. Tip-enhanced Raman spectroscopy can see more: the case of cytochrome c. J. Phys. Chem. C 112 4867-4873.

Zhang, S., Greenfield, M.A., Mata, A., Palmer, L.C., Bitton, R., Mantei, J.R., Aparicio, C., de la Cruz, M.O., Stupp, S.I., 2010. A self-assembly pathway to aligned monodomain gels. Nat. Mater. 9, 594-601.

Zhang, S., Holmes, T.C., DiPersio, C.M., Hynes, R.O., Su, X., Rich, A., 1995. Selfcomplementary oligopeptide matrices support mammalian cell attachment. Biomaterials 16, 1385-1393.

Zhang, S.G., Holmes, T., Lockshin, C., Rich, A., 1993. Spontaneous assembly of a selfcomplementary oligopeptide to form a stable macroscopic membrane. Proc. Natl. Acad. Sci. U.S.A. 90, 3334-3338.

Zhou, M., Smith, A.M., Das, A.K., Hodson, N.W., Collins, R.F., Ulijn, R.V., Gough, J.E., 2009. Self-assembled peptide-based hydrogels as scaffolds for anchoragedependent cells. Biomaterials 30, 2523-2530. 